PERIN, Andrea. "La redefinición de la culpa (imprudencia) penal médica ante el fenómeno de la medicina defensiva. Bases desde una perspectiva comparada".

Polit. crim. Vol. 13, No 26 (Diciembre 2018) Art. 6, pp. 858-903.

[http://www.politicacriminal.cl/Vol_13/n_26/Vol13N26A6.pdf]

\title{
La redefinición de la culpa (imprudencia) penal médica ante el fenómeno de la medicina defensiva. Bases desde una perspectiva comparada
}

\section{The Redefinition of Criminal Medical Negligence facing Defensive Medicine: Laying the Groundwork from a Comparative Perspective}

\author{
Andrea Perin* \\ Profesor de Derecho Penal \\ Universidad Católica del Norte \\ andrea.perin@ucn.cl
}

\section{Resumen}

Frente al fenómeno de la medicina defensiva, una opción político-criminal consiste en reducir el alcance de la culpa (imprudencia) penal médica como criterio de imputación, con el objetivo de conjugar, por un lado, el principio de responsabilidad y, por otro lado, la implementación de mejores condiciones para el ejercicio de la actividad médica y la protección de los bienes jurídicos involucrados. En este sentido, la presente contribución analiza críticamente las reformas adoptadas por el legislador italiano en 2012 y 2017, y algunos aspectos propios de la "imprudencia profesional" regulada por el Código Penal español; poniendo un especial énfasis, en ambos contextos, a la problemática noción de “impericia". En las conclusiones se ofrecen algunas advertencias y sugerencias deducibles desde la perspectiva comparada tenida en consideración. En particular, se muestran los límites de la heterointegración normativa del cuidado debido a través de protocolos y guidelines; se defiende la oportunidad de distinguir entre pautas de cuidado "típicas" (leges artis predeterminadas) y expectativas de cuidado "atípicas" (definibles en el marco del juicio); y, sobre esa base, se propone un criterio de culpa (imprudencia) grave para las hipótesis de culpa médica in eligendo.

Palabras clave: Mala praxis médica, Medicina defensiva, Imprudencia profesional, Culpa (imprudencia) grave, Art. 491 del Código Penal chileno, Derecho comparado, Reforma penal

\begin{abstract}
One of the possible political-criminal options, when facing the phenomenon of Defensive Medicine, consists in reducing the scope of criminal negligence as a criterion of imputation in the field of medical malpractice law, with the aim of combining, on the one hand, the principle of responsibility and, on the other hand, the implementation of better conditions for the protection of the fundamental rights involved. In this regard, the author analyses the reforms adopted by the Italian legislator in 2012 and 2017 and the "professional negligence" as provided by the Spanish Penal Code. The conclusions offer some suggestions and warnings inferable from the comparative perspective considered. In particular, the author argues some limits of the normative heterointegration of the duty of care by protocols and guidelines; he defends a distinction between "typical" (predetermined) standards of care and
\end{abstract}


Polit. crim. Vol. 13, No 26 (Diciembre 2018) Art. 6, pp. 858-903.

[http://www.politicacriminal.cl/Vol_13/n_26/Vol13N26A6.pdf]

"atypical" duties of care (definable within the framework of a trial); and, on that basis, he proposes a criterion of "gross negligence" for the hypothesis of medical culpa in eligendo.

Keywords: Medical Malpractice, Defensive Medicine, Professional Negligence, Gross Negligence, Art. 491 Chilean Penal Code, Comparative Law, Penal Reform

Sumario: 1. La expansión de la culpa (imprudencia) penal - 2. La criminalización de la actividad médica - 3. El fenómeno de la medicina defensiva - 4. Una estrategia políticocriminal - 4.1. El retroceso de la intervención penal - 4.2. Redefinir el alcance de la culpa médica: la exigibilidad (objetiva y subjetiva) y la heterointegración del cuidado debido - 4.3. Despenalizar la culpa: la inconsciente, o también la consciente - 5. Reformas recientes en materia de culpa médica: la experiencia italiana - 5.1. El contexto - 5.2. La reforma Balduzzi (2012) - 5.3. La reforma Gelli-Bianco (2017) - 6. La culpa médica como categoría especial 6.1. La fragmentación de la categoría - 6.2. La "imprudencia profesional" en la experiencia española. 6.3. Una crítica al concepto de "impericia" como medio de discriminación a efectos de la penalidad - 7. Síntesis y bases para una propuesta dogmática. A propósito del art. 491 del Código Penal chileno - 8. Cuestiones abiertas y perspectivas. - Bibliografía

\section{La expansión de la culpa (imprudencia) penal}

En el concierto europeo continental, muchos estudios monográficos relevantes en materia de "imprudencia" o "culpa" penal ${ }^{1}$ toman como punto de partida la observación del incremento explosivo de los delitos culposos (“cuasi-delitos”, en la terminología empleada por el Código

* Este artículo ha sido elaborado en el marco del proyecto Fondecyt Iniciación $\mathrm{N}^{\circ}$ 11170924, "La criminalización de la actividad médica. Nuevas estrategias de política criminal ante el fenómeno de la medicina defensiva", del cual el autor es investigador responsable. Una parte de la contribución tiene su origen en la exposición realizada en la Universidad Católica del Norte (Antofagasta, Chile), en ocasión de las XIV Jornadas Nacionales de Derecho Penal y Ciencias Penales, el día 16 de Noviembre de 2017. Les agradezco a la Profesora Tatiana Vargas Pinto y a los Profesores Héctor Hernández Basualto y José Á. Fernández Cruz por las preguntas y los comentarios recibidos en dicha oportunidad, los que permitieron matizar algunas cuestiones abordadas en este trabajo. Otra parte se ha desarrollado durante una estancia de investigación realizada en la Universidad de Trento (Italia), entre Diciembre de 2017 y Enero de 2018. Le agradezco al Profesor Alessandro Melchionda por su precioso apoyo. Una versión preliminar del trabajo fue luego presentada en el workshop sobre "El Derecho Penal ante la Medicina Defensiva", organizado junto con el grupo de investigación "Cátedra de Derecho y Genoma Humano" de la Universidad del País Vasco (España), y realizado el día 21 de Febrero de 2018 en la Facultad de Derecho (sección Bizkaia) de la misma casa de estudios. Les agradezco a todos los participantes por su valiosa aportación, especialmente al Profesor Carlos M. Romeo Casabona por su gran apoyo en todo. Finalmente, muchas gracias también al Dr. Juan P. Castillo Morales por la revisión del borrador en español.

${ }^{1}$ Una aclaración terminológica y conceptual: de aquí en adelante se aludirá al término culpa, como equivalente lingüístico y dogmático de Fahrlässigkeit (en alemán), colpa (en italiano) y negligence (en la doctrina anglosajona). Más abajo haré referencia al concepto de imprudencia -empleado por la doctrina y la jurisprudencia española sobre todo a partir de la entrada en vigor del Código Penal de 1995-, para hacer referencia al concepto de imprudencia profesional (categoría prevista por el mismo Código español). Esta opción terminológica, inusual pero legítima ante la pluralidad de términos a los que acude el Código Penal chileno para regular la misma categoría dogmática ("culpa", art. 2; "imprudencia", arts. 490 y 492 ; "negligencia", arts. 491 y 492) se debe a la necesidad argumentativa de aludir -de forma crítica- a las tres especies canónicas de esta clase de responsabilidad (imprudencia, negligencia e impericia). Ver las § 6.2 y 6.3. Sin perjuicio de lo anterior, y para evitar posibles malentendidos, cabe señalar al lector que toda la reflexión se desarrolla en el marco de una concepción normativa de la culpa (imprudencia). 
PERIN, Andrea. "La redefinición de la culpa (imprudencia) penal médica ante el fenómeno de la medicina defensiva. Bases desde una perspectiva comparada".

Penal chileno). Esto es así al menos desde fines de los años cincuenta del siglo pasado ${ }^{2}$. Desde entonces han pasado alrededor de sesenta años y en pocas décadas hemos pasado de la sociedad motorizada de la posguerra a la edad de la revolución biotecnológica y de las denominadas "tecnologías emergentes" (en todo el mundo) ${ }^{3}$. Asimismo, hemos reconocido que entre la realización de acontecimientos adversos y la progresiva tecnificación de nuestra sociedad existe una estrecha relación, dada por la inevitabilidad de aquéllos también por razón de ésta ${ }^{4}$. Por ello, el "problema culposo", entendido al mismo tiempo como un desafío conceptual y práctico, se ha superpuesto cada vez más al estudio de su fenomenología.

Muchos de los esfuerzos hechos por la doctrina más reciente para explicar el aumento de la responsabilidad culposa en la sociedad contemporánea se han centrado, precisamente, en el estudio de las relaciones de la culpa -entendida como clase de responsabilidad y criterio de imputación- con las ocasiones o circunstancias que favorecen su emersión en el derecho vivo. Estas relaciones reflejan muy a menudo la progresiva (imparable, inevitable) tecnificación de nuestro vivir. Piénsese -más allá de los accidentes de tráfico- en las enfermedades profesionales provocadas por el uso de sustancias o productos peligrosos en la industria $^{5}$, en los efectos de la contaminación ambiental, en los desastres tecnológicos en general $^{6}$. Y en el debate que, en estos contextos, se ha ido desarrollando acerca de la posibilidad -defendida por algunos y rechazada rotundamente por otros- de aplicar el denominado "principio de precaución" al derecho penal de la culpa 7 .

Como lo demuestra el debate que se acaba de mencionar, sería sin embargo un error reducir la expansión de esta clase de responsabilidad al supuesto incremento de acontecimientos adversos en la sociedad contemporánea, pues el aumento de juicios y sentencias de condena depende de la valoración que de los hechos ocurridos hagan, en primer lugar, las supuestas víctimas, y los jueces, después.

\footnotetext{
${ }^{2}$ Por todos, y con más referencias, véanse: QUINTANO RIPOLLÉS, Antonio, Derecho penal de la culpa (imprudencia), Barcelona: Bosch, 1958, p. 10, 105 s.; WELZEL, Hans, Fahrlässigkeit und Verkehrsdelikte. Zur Dogmatik der fahrlässigen Delikte, Karlsruhe: Müller, 1961, p. 5 s.; MARINUCCI, Giorgio, La colpa per inosservanza di leggi, Milano: Giuffrè, 1965, p. 2, nota 10; FORTI, Gabrio, Colpa ed evento nel diritto penale, Milano: Giuffrè, 1990, p. 2 s.

${ }^{3}$ Véase ROMEO CASABONA, Carlos María (Ed.), Tecnología convergentes: Desafíos éticos y jurídicos, Cátedra Interuniversitaria de Derecho y Genoma Humano - Comares: Bilbao - Granada, 2016.

${ }^{4}$ Sobre esta relación, entre otros: CENTONZE, Francesco, La normalità dei disastri tecnologici. Il problema del congedo dal diritto penale, Milano: Giuffrè, 2004; ROMEO CASABONA, Carlos María, Conducta peligrosa e imprudencia en la sociedad de riesgo, Granada: Comares, 2005.

5 Véase, con más referencias, PERIN, Andrea, "La crisi del 'modello nomologico' fra spiegazione e prevedibilità dell'evento nel diritto penale. Note introduttive e questioni preliminari sul fatto tipico colposo", Rivista italiana di diritto e procedura penale, Vol. 57, $\mathrm{n}^{\circ} 3$ (2014), pp. 1371-1409, p. 1384, 1391 s., 1404-6.

${ }^{6}$ FORTI, Colpa, cit. nota no 2, p. 38 s.; CENTONZE, La normalità, cit. nota no 4, p. 7 s.; LAUTA, Kristian C., Disaster Law, Abingdon - New York: Routledge, 2015, p. 11 s., 105 s.

${ }^{7} \mathrm{La}$ cuestión es si, dado que "los peligros a los cuales estamos expuestos pertenecen a un siglo distinto de aquel del que provienen las promesas de seguridad que procuran dominarlos" (BECK, Ulrich, Conditio humana. Il rischio nell'età globale, Roma - Bari: Laterza, 2011, p. 48-9, trad. esp. propia), las exigencias de tutela emergentes de las nuevas fuentes de riesgo pueden legitimar una revisión de las categorías dogmáticas tradicionales. Para una presentación de este debate, más referencias y algunas propuestas, véase: PERIN, Andrea, "La condotta lesiva colposa. Una prospettiva ricostruttiva", Política Criminal, Vol. 12, no 23 (2017), pp. 207-266, p. 210, 218-222, 240 s., 247 s., en: http://www.politicacriminal.cl/Vol_12/n_23/Vol12N23A7.pdf [visitado el 12.01.2018].
} 
La imputación de responsabilidades supone un proceso valorativo, no ya una mera constatación causal-objetiva. Así, por ejemplo, el hecho de haber materialmente provocado -o bien, no haber evitado, hallándose el sujeto imputado en posición de garante- un perjuicio penalmente relevante (i.e., que supone la afectación de bienes jurídicos penalmente protegidos) no implica necesariamente tener que responder por ello. Es el proceso intelectual (discrecional, regulado por criterios y parámetros normativos) de evaluación y adscripción lo que permite calificar una intervención dañina como un error grave e injustificable, o un accidente laboral, de tráfico, etc., como un homicidio. No consideramos sólo hechos y resultados lesivos, sino actos negligentes, imprudentes o imperitos; esto es, conductas lesivas culposas.

Esto no es baladí, pues no debemos olvidar que la concepción de la "culpa penal" como un quid normativo conceptualmente distinto de la relación de causalidad, por un lado, y de un mero déficit de atención (o una voluntad defectuosa), por otro, representa una asunción teórica que, aun habiéndose impuesto en la doctrina de la tradición jurídica europeo continental desde las primeras décadas del siglo pasado, todavía no ha sido asumida del todo por la jurisprudencia.

\section{La criminalización de la actividad médica}

Frente a la expansión señalada en la introducción, el sector de la responsabilidad médica no constituye ninguna excepción. En efecto, en muchos países comparables desde el punto de vista económico y socio-cultural, desde hace décadas (desde principios de los años sesenta del siglo pasado, empezando por los EE.UU.) se asiste a un aumento progresivo de demandas, denuncias y condenas por supuestos actos de mala praxis médica ${ }^{8}$.

En estos contextos, la cada vez mayor capacidad asistencial de los sistemas de salud y el

\footnotetext{
${ }^{8}$ Véanse, para algunos datos y más referencias: BARREDA, Iñigo, "La medicina defensiva: Tendencias y experiencias en el ámbito internacional”, Revista Conamed, Vol. 4, no 13 (1999), pp. 18-21; ORTEGA GONZÁLEZ, Manuel; MÉNDEZ RODRÍGUEZ, Juan Manuel; LÓPEZ-LÓPEZ, Fidel, "Medicina defensiva, su impacto en las instituciones de salud", Revista Conamed, Vol. 14 (2009), pp. 4-10; GUERRA, Giorgia, "La medicina difensiva: fenomeno moderno dalle radici antiche", Politiche sanitarie, Vol. 14, no 4 (2013), pp. 221225. "Que la responsabilidad médica se ha expandido durante las últimas décadas es algo que no se discute": así DE LA MAZA, Iñigo, "Presentación", Responsabilidad médica, Cuadernos de análisis jurídico - Colección de Derecho Privado VI, Santiago: Ediciones Universidad Diego Portales, 2010, pp. 9-11, p. 9 (con más referencias); en el mismo sentido, en la discusión chilena: MARTÍNEZ, Marco, "La graduación del deber de cuidado en el delito culposo por Actos de mala praxis médica: un análisis dogmático, jurisprudencial y económico", Política Criminal, Vol. 6, $\mathrm{n}^{\mathrm{o}} 12$ (2011), pp. 214-252, p. 218, en: http://www.politicacriminal.cl/Vol_06/n_12/Vol6N12A1.pdf [visitado el 12.01.2018]; ROSAS OLIVA, Juan Ignacio, "La delimitación del deber de cuidado en la imputación de responsabilidad penal por imprudencia médica", Doctrina y jurisprudencia penal. Imprudencia penal médica, $\mathrm{n}^{\circ} 5$ (2011), pp. 3-34, p. 3 s., y nota 2; MIRANDA SUÁREZ, Francisco, "Demandas por responsabilidad médica en Chile. Análisis de montos, condenas y duración", Revista de Derecho. Escuela de Postgrado, nº 7 (2015), pp. 79-102, p. 81 s.; VARGAS PINTO, Tatiana, "Algunos antecedentes sobre el complejo "deber de previsión" médico", Revista de Derecho (Valdivia), Vol. XXX, no 1 (2017), pp. 351-375, p. 352, en: http://www.scielo.cl/pdf/revider/v30n1/art15.pdf [visitado el 12.01.2018].
} 
PERIN, Andrea. "La redefinición de la culpa (imprudencia) penal médica ante el fenómeno de la medicina defensiva. Bases desde una perspectiva comparada".

aumento de la expectativa de vida indudablemente ofrecen una primera base explicativa del fenómeno señalado. Ambos factores suponen, en primer lugar, un aumento cuantitativo de los actos médicos $\mathrm{y}$, por ende, mayores probabilidades de que se realicen actos de mala praxis. Pero, ante todo, dichos factores también suponen un cambio cualitativo de dichos actos, caracterizándose este cambio por un intervencionismo progresivo de la medicina en ámbitos que hasta hace treinta o cuarenta años estaban totalmente fuera de su alcance ${ }^{9}$.

Nos enfrentamos con una medicina cada vez más técnica y agresiva. Este es otro factor clave para comprender mejor el fenómeno en cuestión en al menos dos sentidos ulteriores. Primero, porque la progresiva tecnificación de la actividad curativa lleva consigo la especialización de quienes la ejercen. Y dicha especialización puede favorecer errores en la interpretación y/o en el tratamiento de aquellos casos clínicos que requieren una visión de conjunto del estado del paciente por parte de un equipo médico interdisciplinario ${ }^{10}$. Segundo, porque si bien es cierto que el empleo de medidas diagnósticas y terapéuticas avanzadas puede conllevar mayores ventajas, éstas también pueden suponer mayores riesgos para la salud de los pacientes ${ }^{11}$.

Una medicina cada vez más técnica e invasiva genera también nuevas expectativas en la población y supone, precisamente por eso, un cambio cultural. La técnica genera así también nuevas exigencias, las cuales encuentran nuevos espacios de reivindicación en el contexto dado por la transición del paradigma paternalista a una relación médico-paciente basada en el principio de autonomía y tendiente a configurarse (cada vez más) como una relación

\footnotetext{
${ }^{9}$ Piénsese en las técnicas de reanimación, que abrieron el escenario del debate contemporáneo sobre el fin de vida (véanse las reflexiones de BERNARDINI, Daniele, "Curarsi vs. Prendersi cura. Le scelte del fine vita", Quaderni Vicentini, n $^{\circ} 5$ (2017), pp. 87-94, p. 89 s.), y las técnicas de reproducción asistida (véase, en la doctrina más reciente, FEMENÍA LÓPEZ, Pedro J., "Nuevos perfiles jurídicos del acto médico: responsabilidad derivada del screening genético", Revista de Derecho y Genoma Humano. Genética, Biotecnología y Medicina Avanzada, $\mathrm{n}^{\circ} 46$ (2017), pp. 143-176). Además, a propósito de la progresiva "medicalización" de muchos aspectos de la vida, antes indiferentes a la medicina, en las distintas ediciones del Diagnostic and Statistical Manual of Mental Disorders de la American Psychiatric Association (en particular, del DSM-III de 1980 en adelante), véanse las reflexiones críticas de GRECO, Monica, "What is the DSM? Diagnostic manual, cultural icon, political battleground: an overview with suggestions for a critical research agenda", Psychology \& Sexuality, Vol. 7, Issue 1 (2016), pp. 6-22, en: https://doi.org/10.1080/19419899.2015.1024470 [visitado el 14.06.2018].

${ }^{10}$ Por ello, con el fin de evitar o remediar posibles errores, se ha defendido la oportunidad de exigir, en ciertas circunstancias, la adopción, a nivel de protocolos, de formas de control mutuo, descartando así la vigencia del principio de confianza. A este propósito: MARAVER GÓMEZ, Mario, El principio de confianza en Derecho penal. Un estudio sobre la aplicación del principio de autorresponsabilidad en la teoría de la imputación objetiva, Cizur Menor: Civitas - Thomson Reuters, 2009, p. 404; cfr. RISICATO, Lucia, L'attività medica di équipe tra affidamento e obblighi di controllo reciproco. L'obbligo di vigilare come regola cautelare, Torino: Giappichelli, 2013, p. 20 s., 31 s., 71 s.

${ }^{11}$ ROMEO CASABONA, Carlos María, El médico y el Derecho Penal, t. II, Vol. 1, Los problemas penales actuales de la Biomedicina, Santa Fe: Rubinzal-Culzoni, 2011, p. 243 s. Piénsese, p. ej., en la evolución de la ingeniería genética aplicada a la salud humana y, en particular, al debate que se ha desarrollado en los últimos años acerca de la técnica de genome editing denominada CRISPR-Cas 9 , frente a los riesgos de accidentes biológicos y mutaciones genéticas que su aplicación podría generar. Véase BERGEL, Salvador Darío, "Aspectos éticos y jurídicos de la edición genética humana", Revista de Derecho y Genoma Humano. Genética, Biotecnología y Medicina Avanzada, $\mathrm{n}^{\circ} 46$ (2017), pp. 15-35.
} 
Polit. crim. Vol. 13, No 26 (Diciembre 2018) Art. 6, pp. 858-903.

[http://www.politicacriminal.cl/Vol_13/n_26/Vol13N26A6.pdf]

contractual y pseudomercantil ${ }^{12}$.

Los pacientes somos cada vez más conscientes de nuestros derechos en materia de salud. Sin embargo, si por un lado esto se puede ver como un avance a nivel general, esas nuevas expectativas alimentan la ya endémica tendencia de la sociedad de atribuirle a la medicina el poder de evitar lo inevitable, como si tuviese un dominio absoluto sobre la naturaleza y sobre nuestros destinos como parte de ella. Esto lleva a no aceptar su falibilidad como técnica curativa - ni la falibilidad de quienes están llamados para aplicarla (el error humano) ${ }^{13}$ - y a ser más proclives a reclamar, denunciar y pedir indemnizaciones frente a resultados desfavorables que asumimos provocados por errores médicos ${ }^{14}$.

Esta "imagen" $" 15$ cientificista de la medicina ${ }^{16}$-fomentada por nuestra educación escolar esencialmente positivista, el nefasto papel de los medios de comunicación y la idea que de sí mismos tienen muchos de sus operadores- va generando expectativas no sólo nuevas, sino también excesivas respecto del nivel de cuidado exigible a quienes la ejercen. Y cuando éstas expectativas acceden a los tribunales de justicia como elementos de "precomprensión"17, se pueden convertir en parámetros normativos idóneos para respaldar sentencias de condena.

La culpa, entendida como categoría y criterio de imputación, surge del dualismo generado

\footnotetext{
${ }^{12}$ Sobre este cambio de paradigma, entre otros: MONTANARI VERGALLO, Gianluca, Il rapporto medicopaziente. Consenso e informazione tra libertà e responsabilità, Milano: Giuffrè, 2008, p. 3 s.; ROMEO CASABONA, El médico (t. II), cit. nota $\mathrm{n}^{\mathrm{o}}$ 11, p. 121 s. En particular, sobre la mercantilización de la relación médico-paciente y la pérdida progresiva del respeto histórico por el médico a nivel social, URRUELA MORA, Asier, El derecho penal ante el fenómeno de las agresiones a profesionales sanitarios, Granada: Comares, 2017 , p. 7 s.

${ }^{13}$ MAGLIO, Ignacio, "Error y medicina a la defensiva: ética médica y la seguridad del paciente", Revista Bioética, Vol. 19, n 2 (2011), pp. 359-365, p. 360; FREITAS DRUMOND, José Geraldo, ¿Será la medicina defensiva el futuro de la medicina?, Gaceta Internacional de Ciencias Forenses, no 14 (2015), pp. 3-4, p. 4.

${ }^{14}$ Destacan este aspecto, entre otros: HAVA GARCÍA, Esther, La imprudencia médica, Valencia: Tirant lo Blanch, 2001, p. 11 s.; PAREDES SIERRA, Raymundo; RIVERO SERRANO, Octavio, "Medicina defensiva", en: TONIMOTO, Miguel; RIVERO SERRANO, Octavio (Coords.), El ejercicio actual de la medicina, Facultad de Medicina UNAM - Siglo XXI Editores, 2003, pp. 79-89, p. 82 s.

${ }^{15}$ Me refiero al concepto de "image of science" utilizado, entre otros, por VILLA, Vittorio, Teorie della scienza giuridica e teorie delle scienze naturali. Modelli ed analogie, Milano: Giuffrè, 1984, p. 22, nota 33 y passim; LICCI, Giorgio, Immagini di conoscenza giuridica, Padova: Cedam-Wolters Kluwer Italia, 2011, p. 21 s., quienes aluden a los diversos modos de entender la ciencia presupuestos por los "constructores de teorías". Según destacan estos autores, las imágenes de ciencia, o sea, las maneras de concebir y entender el conocimiento, sus fuentes, su validez, etc., defendidas en la epistemología contemporánea, descansan en modelos más generales que suponen asunciones asimismo generales de variada naturaleza (metafísicas, sobre la vida, visiones globales del mundo, etc.), las cuales, a su vez, se traducen en distintos modelos de cientificidad. ${ }^{16}$ Habla expresamente de "cientificismo superficial", entre los penalistas, VALLINI, Antonio, "Paternalismo medico, rigorismo penali, medicina difensiva: una sintesi problematica e un azzardo de iure condendo", Rivista italiana di medicina legale, Vol. XXXV, $\mathrm{n}^{\circ} 1$ (2013), pp. 1-16, p. 2. Véase además la literatura citada por MIRANDA SUÁREZ, "Demandas”, cit. nota n 8 , nota 1 .

${ }^{17}$ El concepto de "precomprensión" se refiere a la influencia determinante ejercida en el desempeño de la discrecionalidad judicial por una serie de "factores contextuales de carácter extra-textual, como por ejemplo el contexto político-cultural, preocupaciones de política-penal judiciaria (...), la cultura, la ideología y la sensibilidad del juez particular": así, FIANDACA, Giovanni, Prima lezione di diritto penale, Bari - Roma: Laterza, 2017, nota 81 (trad. propia).
} 
PERIN, Andrea. "La redefinición de la culpa (imprudencia) penal médica ante el fenómeno de la medicina defensiva. Bases desde una perspectiva comparada".

por el incumplimiento de una expectativa normativa que, en última instancia, es una expectativa de origen social (descanse o no el deber de cuidado también en normas tecnocientíficas $^{18}$ ).

Pero hay más. En efecto, a este elemento cultural -herencia del naturalismo dominante en el siglo XIX- se superpone la epistemología de la incertidumbre, esto es, aquel conjunto heterogéneo de teorías del conocimiento que arguyen la incapacidad de las ciencias empíricas de proporcionarnos explicaciones de la realidad necesariamente concluyentes, ciertas, indiscutibles y definitivas ${ }^{19}$.

La idea epistemológica de incertidumbre descansa en la insostenibilidad del positivismo científico y supone, por el contrario, la relatividad de todo conocimiento. Pero dicha relatividad, entendida en su contexto epistemológico originario como un carácter propio del conocimiento (hipotético, provisorio, válido sólo dentro de ciertos $-\mathrm{y}$ no otros- modelos explicativos o paradigmas científicos, etc. ${ }^{20}$ ), se convierte -a menudo impropiamente- en una actitud de desconfianza ideológica e irracional hacia las instituciones a las cuales tradicionalmente corresponde trasmitir el conocimiento a la sociedad (universidades, centros de investigación, etc.). Su asunción fomenta la idea según la cual todo conocimiento es no sólo discutible, sino también democrático, e influye en el conjunto social -por ende, fuera de su contexto originario- hasta el punto de poner el tema de la credibilidad de los enunciados científicos constantemente sobre la mesa del debate público.

En las últimas décadas, este fenómeno se ha hecho evidente precisamente en el campo específico de la medicina. Piénsese, por ejemplo, en el (impropiamente) denominado "negacionismo del SIDA" 21 o en el más reciente movimiento anti-vacunas. La llamada "medicina oficial" -también por su escasa capacidad autocrítica o, dicho en una palabra, su cientificismo- se sienta cada vez con mayor frecuencia en el banquillo de los acusados; en su contra se dirigen cada vez más demandas de reparación, y los tribunales de justicia se convierten muy a menudo -por paradójico que parezca- en depositarios involuntarios de la

\footnotetext{
${ }^{18}$ Para una crítica a la "objetivización" de las normas de cuidado por medio de fuentes o parámetros técnicos, con especial referencia a la doctrina que defiende la necesidad de precisar el parámetro normativo de diligencia por medio del criterio pseudotécnico de la "mejor ciencia y experiencia", véase PERIN, "La crisi", cit. nota n 5, p. $1401 \mathrm{~s}$.

${ }^{19}$ En la literatura jurídica, véanse: TALLACCHINI, Maria C., "Before and beyond the precautionary principle: Epistemology of uncertainty in science and law". Toxicology and Applied Pharmacology, Vol. 207, Issue 2 (2005), pp. 645-651, en: http://www.sciencedirect.com/science/article/pii/S0041008X05003303?via\%3Dihub [visitado el 12.01.2018]; ESTEVE PARDO, José, El Desconcierto del Leviatán. Política y Derecho ante las Incertidumbres de la Ciencia, Barcelona: Marcial Pons, 2009, p. 30 s.

${ }^{20}$ Sobre el concepto de "paradigma científico" (aplicable, mutatis mutandis, también a nuestra ciencia penal: piénsese p. ej. en el pasaje de la concepción psicológica a la concepción normativa de la culpabilidad, a principios del siglo pasado), KUHN, Thomas S., The Structure of Scientific Revolutions (1962), ChicagoLondon: The University of Chicago Press, 2012.

${ }^{21}$ Véanse p. ej.: KALICHMAN, Seth C., Denying AIDS: Conspiracy Theories, Pseudoscience, and Human Tragedy, New York: Springer, 2009; PREDA, Alex, AIDS, Rhetoric, and Medical Knowledge, Cambridge: Cambridge University Press, 2005.
} 
Polit. crim. Vol. 13, No 26 (Diciembre 2018) Art. 6, pp. 858-903.

[http://www.politicacriminal.cl/Vol_13/n_26/Vol13N26A6.pdf]

supuesta "verdad científica"22.

\section{El fenómeno de la medicina defensiva}

Semejante exigencia de justicia o, dicho más prosaicamente, de indemnización, ha fomentado el fenómeno de la denominada "medicina defensiva", esto es, la tendencia de los profesionales de la salud, condicionados por el temor a la sanción, a desviarse del criterio teleológico (exclusivo) del mejor resultado para el paciente, para actuar conforme el objetivo principal de alejar -o al menos disminuir- el riesgo de incurrir en algún tipo de responsabilidad $^{23}$.

El temor a la sanción se puede convertir en el primer criterio de actuación de los profesionales, llevándolos a excederse en el uso de cuidados médicos (piénsese, por ejemplo, en la sobreindicación de medidas diagnósticas de alta complejidad, en la prescripciones innecesarias de fármacos y en la superposiciones de terapias), para que no se les pueda reprochar ninguna falta u omisión (medicina defensiva "positiva"), o bien a deshacerse de los casos clínicos más complejos, o con menores probabilidades de éxito, esto es, aquellos casos que exigirían acudir a tratamientos o estrategias terapéuticas más arriesgadas e inciertas en cuanto a los beneficios alcanzables para el paciente (medicina defensiva "negativa") ${ }^{24}$.

\footnotetext{
${ }^{22}$ A propósito de las corrientes anti-vacunas, hay que recordar que el médico británico Andrew Wakefield defendió la existencia de una relación entre las vacunas y el autismo en un trabajo publicado en la revista The Lancet en 1998. Sin embargo, esta publicación fue retirada en 2010, porque según el UK General Medical Council's Fitness to Practise Panel de 28 de enero de 2010, "it has become clear that several elements of the 1998 paper by Wakefield et al. are incorrect, contrary to the findings of an earlier investigation. In particular, the claims in the original paper that children were "consecutively referred" and that investigations were "approved" by the local ethics committee have been proven to be false": THE LANCET (EDS.), "RetractionIleal-lymphoid-nodular hyperplasia, non-specific colitis, and pervasive developmental disorder in children", The Lancet, Vol. 375, Issue 9713 (2010), p. 445. La comunidad científica va claramente en el sentido de rechazar la hipótesis de la existencia de dicha relación: entre los estudios más citados, DE STEFANO, Frank; PRICE, Cristofer S.; WEINTRAUB, Eric S., "Increasing Exposure to Antibody-Stimulating Proteins and Polysaccharides in Vaccines Is Not Associated with Risk of Autism", The Journal of Pediatrics, Vol. 163, Issue 2 (2013), pp. 561-567. No obstante lo anterior, en Italia algunos tribunales han reconocido indemnizaciones sobre la base de la hipótesis cuestionada: ver, para más referencias, el "Dossier: vaccini e autismo", publicado por el grupo de investigación "Biodiritto" de la Universidad de Trento: http://www.biodiritto.org/index.php/novita/news/item/577-dossier-vaccini-e-autismo; y el estudio de TOMASI, Marta, "Uniformità della giurisprudenza e unitarietà della scienza: la misura di sostenibilità del pluralismo", BioLaw Journal, $\mathrm{n}^{\mathrm{o}} 1$ (2016), $\quad$ pp. $\quad 81-103, \quad$ p. $\quad 93 \quad$ s., $\quad$ en: http://www.biodiritto.org/ojs/index.php?journal=biolaw\&page=article\&op=view\&path\%5B\%5D=128

[visitado el 31.05.2018].

23 "Defensive medicine occurs when doctors order tests, procedures or visits, or avoid high-risk patients or procedures, primarily (but not necessarily solely) to reduce their exposure to malpractice liability": U.S. CONGRESS - OFFICE OF TECHNOLOGY ASSESSMENT, Defensive Medicine and Medical Malpractice, Washington DC: U.S. Government Printing Office, 1994, p. 21.

${ }^{24}$ Sobre las prácticas de medicina defensiva, ver p. ej.: SCLAR, David; HOUSMAN, Michael, "Medical Malpractice and Physician Liability: Examining Alternatives to Defensive Medicine", Harvard Health Policy Review, Vol. 4, no 1 (2003), pp. 75-84, p. 76, en: https://ssrn.com/abstract=924294 [visitado el 12.01.2018]; GUERRA, Giorgia, "La medicina”, cit. nota nº 8, p. 222; FRAKES, Michael D., "The Surprising Relevance of Medical Malpractice Law", University of Chicago Law Review, Vol. 82, Issue 1 (2015), pp. 317-391, p. 344 s., en: https://chicagounbound.uchicago.edu/uclrev/vol82/iss1/13 [visitado el 25.04.2018]; TINICA, Grigore;
} 
PERIN, Andrea. "La redefinición de la culpa (imprudencia) penal médica ante el fenómeno de la medicina defensiva. Bases desde una perspectiva comparada".

Las prácticas de medicina defensiva, a su vez, traen consigo consecuencias negativas muy estrechamente relacionadas entre sí.

Desde un primer punto de vista, esta actitud puede originar graves alteraciones en la relación médico-paciente, que deja de desarrollarse en condiciones de mutua confianza ${ }^{25}$ y sobre la base de los principios rectores de beneficencia, no maleficencia y autonomía ${ }^{26}$. Esto sucede, por ejemplo, cuando los médicos recurren al consentimiento como instrumento mediante el cual desplazar toda responsabilidad (y el riesgo) al propio paciente (pese a que, como sabemos, el consentimiento del paciente al acto médico en ningún caso ampara la actuación incorrecta -es decir, negligente de por sí- del profesional ${ }^{27}$; o bien, cuando se sobreutilizan pruebas radiológicas o medicamentos. Estas conductas pueden exponer a los pacientes (o incluso a la población mundial, cuando por ejemplo se trate de antibióticos) a mayores riesgos de sufrir perjuicios evitables, y en algunos casos graves e irreversibles ${ }^{28}$, incrementándose de esta forma la desconfianza y el aumento de juicios ${ }^{29}$.

Bien conocidos son, finalmente, los efectos negativos de carácter económico asociados a la gestión irracional de los recursos humanos y materiales de los sistemas públicos y privados de salud, todo lo cual supone graves perjuicios a su funcionamiento (menores beneficios, aumento de costos, ineficiencia) ${ }^{30}$.

TOMAZIU-TODOSIA, Mihaela; TOMAZIU-TODOSIA Gabriel-Catalin; CHISTOL, Raluca Ozana; BULGARU-ILIESCU, Diana; FURNICA Cristina, "Defensive Medicine: Myths and Realities", en: IGNATESCU, C., SANDU, A., CIULEI, T. (Eds.), Rethinking Social Action. Core Values in Practice, Suceava: Lumen Proceedings, 2017, pp. 898-910, p. 901 s., en: https://doi.org/10.18662/lumproc.rsacvp2017.82 [visitado el 12.01.2018].

${ }^{25}$ PAREDES SIERRA; RIVERO SERRANO, "Medicina", cit. nota no 13, p. 80; MAGLIO, "Error", cit. nota $\mathrm{n}^{\circ} 13$, p. 362

${ }^{26}$ Ver, sobre la relación en ocasiones antinómica entre los principios de beneficencia y autonomía, LEÓN CORREA, Francisco J., "Autonomía y beneficencia en la ética clínica: ni paternalismo ni medicina defensiva”, Biomedicina, Vol. 2, n 3 (2006), pp. 257-260.

${ }^{27}$ Es decir: el tratamiento médico debe contar con el consentimiento del paciente además de ajustarse al cuidado debido. Al respecto, con más referencias: ROMEO CASABONA, El médico (t. II), cit. nota no 11, p. 125-6; en Chile, VARGAS PINTO, Tatiana, "La imprudencia médica. Algunos problemas de imputación de lo injusto penal", Revista de Derecho UCN, Vol. 17, $\mathrm{n}^{\circ} 2$ (2010), pp. 99-132, p. 120, en: http://revistaderecho.ucn.cl/index.php/rducn/article/view/102/102 [visitado el 12.01.2018]. Sobre la relevancia del consentimiento al tratamiento en la configuración de la responsabilidad médica, y en un sentido parecido, véase: HERNÁNDEZ BASUALTO, Héctor, "Consentimiento informado y responsabilidad penal médica: una relación ambigua y problemática", en: DE LA MAZA GAZMURI, Iñigo (Coord.), Responsabilidad médica, Cuadernos de análisis jurídico - Colección de Derecho Privado VI, Santiago: Ediciones Universidad Diego Portales, 2010, pp. 167-185, p. 170 s.; y ROMEO MALANDA, Sergio, "Responsabilidad penal médica por ausencia del consentimiento informado: un enfoque alternativo a las tesis dominantes", Cuadernos de Política Criminal, $\mathrm{n}^{\circ}$ 110, Época II (2013), pp. 73-113, p. 74 s.

${ }^{28}$ Como, por ejemplo, los daños asociados a la irradiación desmedida e injustificada, por el uso excesivo de TACs (MAGLIO, "Error", cit. nota no 13, p. 362).

${ }^{29}$ En este sentido, la alteración de la relación médico-paciente es, al mismo tiempo, causa y consecuencia de la medicina defensiva (se genera un círculo vicioso).

${ }^{30}$ Más referencias (en contextos distintos) en: KESSLER, Daniel P., "Evaluating the Medical Malpractice System and Options for Reform", The Journal of Economic Perspectives: A Journal of the American Economic Association, Vol. $25 \mathrm{n}^{\circ} 2$ (2011), pp. 93-110, en: https://www.ncbi.nlm.nih.gov/pubmed/21595327 [visitado el 13.01.2018]; ORTEGA GONZÁLEZ; MÉNDEZ RODRÍGUEZ; LÓPEZ-LÓPEZ, "Medicina”, cit. nota nº 8, 
Polit. crim. Vol. 13, No 26 (Diciembre 2018) Art. 6, pp. 858-903.

[http://www.politicacriminal.cl/Vol_13/n_26/Vol13N26A6.pdf]

\section{Una estrategia político-criminal}

\subsection{El retroceso de la intervención penal}

De cara a este fenómeno, cabe preguntarse en qué medida el derecho penal puede replantear su intervención para evitar favorecerlo; y, en particular, cuál sería un modelo de imputación por actos de mala praxis médica que permita conjugar de mejor manera, por un lado, el principio de responsabilidad ${ }^{31}-\mathrm{y}$ las razones simbólicas, preventivas y represivas que explican el ius puniendi-y, por otro, la implementación de las mejores condiciones para el ejercicio de la actividad médica y la protección de los bienes jurídicos involucrados (vida y salud psicofísica).

En este sentido, y asumiendo que la blame culture favorece la medicina defensiva -lo que convierte al derecho penal en un auténtico factor criminógeno ${ }^{32}-$, una de las tendencias de la política criminal actual consiste en tratar de redefinir y limitar el alcance de la responsabilidad penal de los profesionales médico-sanitarios.

Sin embargo, la forma para alcanzar - por el medio de una limitación de la intervención penal- una mejor estrategia de prevención, sigue siendo objeto de debate.

\subsection{Redefinir el alcance de la culpa médica: la exigibilidad (objetiva y subjetiva) y la heterointegración del cuidado debido}

En la dirección de redefinir la culpa como categoría normativa y criterio de imputación de responsabilidad por resultados lesivos, otorgándole un alcance más limitado, se han planteado diversas estrategias dogmáticas, no necesariamente alternativas, sino posiblemente cumulativas.

Una primera opción sería acudir al criterio de la gravedad, exigiendo la culpa grave del profesional. Este resultado, a su vez, podría lograrse, por ejemplo: (a) ajustando el parámetro normativo de precisión del deber de cuidado y bajando, a la inversa, el nivel de exigibilidad objetiva ${ }^{33}$; o bien, (b) sobre la base de la teoría de la "doble medida" o "doble dimensión" de

p. 5 s.; MARTÍNEZ, “La graduación”, cit. nota n 8, p. 220 s.; BARTOLI, Roberto, “I costi 'economicopenalistici' della medicina difensiva", Rivista italiana di medicina legale, no 4-5 (2011), pp. 1107-1123; D’ALESSANDRO, Francesco, “Contributi del diritto alla riduzione della medicina difensiva", Rivista italiana di medicina legale, $\mathrm{n}^{\circ} 3$, (2014), pp. 927-952, nota 4.

${ }^{31}$ ROMEO CASABONA, El médico (t. II), cit. nota $n^{\circ} 11$, p. 49 s., con especial referencia a la ética de la responsabilidad en Max Weber y a su evolución (o acepción) "precautoria” en la contribución de Hans Jonas.

${ }^{32}$ EUSEBI, Luciano, "Medicina difensiva e diritto penale 'criminogeno", Rivista italiana di medicina legale, Vol. XXXIII, no 5 (2011), pp. 1085-1106, p. 1086 s., haciendo hincapié en el carácter casual o fortuito de la responsabilidad culposa en los delitos de resultado, y por ello -en su opinión-desprovista de cualquier eficacia preventiva.

33 Como ha propuesto en términos generales CORNACCHIA, Luigi, Concorso di colpe e principio di responsabilità per fatto proprio, Torino: Giappichelli, 2004, p. 560, según el cual, cuando se trate de resultados lesivos provocados por culpa inconsciente, la conducta debería considerarse típica y punible sólo en el caso de haberse infringido una norma de cuidado exigible a cualquiera. 
PERIN, Andrea. "La redefinición de la culpa (imprudencia) penal médica ante el fenómeno de la medicina defensiva. Bases desde una perspectiva comparada".

la culpa -según la cual, además de la infracción de cuidado debido ("tipo subjetivo”, o "dimensión típica" de la culpa), se requiere la existencia de un poder efectivo de previsión y evitación ("culpabilidad culposa", o "elemento subjetivo de la culpa") ${ }^{34}$-, exigiendo que al sujeto imputado le fuera subjetivamente exigible el cumplimiento del cuidado debido ${ }^{35}$.

Otra manera de redefinir el alcance de la culpa médica sería regular la heterointegración normativa del deber de cuidado del profesional por medio de fuentes técnicas, estableciendo que sólo ciertas normas extrajurídicas (leges artis contenidas o reconocidas por protocolos y guidelines, certificados en su caso por instituciones públicas) puedan determinar el contenido del deber de cuidado del médico, el alcance del error penalmente relevante y, de esta manera, la frontera del "riesgo permitido".

Ambos caminos -la graduación de la responsabilidad médica y la heterointegración normativa del cuidado debido- serán objeto de atentas reflexiones en las secciones 5.1 y siguientes del presente artículo, donde se examinarán críticamente las reformas adoptadas por el legislador italiano en los últimos años (dada la objetiva relevancia de esa experiencia en el derecho comparado actual).

\subsection{Despenalizar la culpa: la inconsciente, o también la consciente}

Si una primera corriente se centra en la limitación del alcance de la culpa, otro camino sería suprimirla, renunciando a sancionar la "culpa inconsciente" -esto es, la culpa puramente normativa, sin representación-, o también a la "consciente" (según se entienda esa noción: con previsión del resultado, o bien con consciencia de la infracción del cuidado debido, aunque sin previsión del resultado ${ }^{36}$ ).

En este sentido, la doctrina sigue preguntándose si la discutible eficacia preventiva y las fuertes necesidades de reparación que harían necesaria la culpa penal, pueden realmente seguir justificando -y hasta qué punto- una intervención de esta naturaleza ${ }^{37}$, sobre todo en el contexto que nos ocupa. Así, se pone cada vez más en duda el papel del derecho penal en

\footnotetext{
${ }^{34}$ Véase, entre otros: FLETCHER, George P., "The Theory of Criminal Negligence. A Comparative Analysis", University of Pennsylvania Law Review, Vol. 119, nº 3 (1971), pp. 401-438, p. 426 s.; BURGSTALLER, Manfred, Das Fahrlässigkeitsdelikt im Strafrecht. Unter besonderer Berücksichtigung der Praxis in Verkehrssachen, Wien: Manz, 1974, p. 182 s.; CASTRONUOVO, Donato, La colpa penale, Milano: Giuffrè, 2009, p. 398 s., 560 s.; DONINI, Massimo, "L’elemento soggettivo della colpa. Garanzie e sistematica", Rivista italiana di diritto e procedura penale, Vol. 56, n $\mathrm{n}^{\mathrm{O}} 1$ (2013), pp. 124-156, p. 137 s., aunque defendiendo una configuración dogmática distinta de la clásica "doble medida"; RUIZ LÓPEZ, Carmen E., La graduación del delito imprudente imprudente. Reflexiones sobre la necesidad de delimitación entre imprudencia leve e imprudencia grave, Bogotá: Universidad Externado de Colombia, 2011, p. 139 s.; en Chile, con especial referencia al sector del que nos ocupamos, VARGAS PINTO, "La imprudencia", cit. nota n 27, p. 123 s.

${ }^{35}$ En este sentido, según defienden algunos autores, el llamado "elemento subjetivo de la culpa" se basaría en el principio de inexigibilidad: en Italia, CASTRONUOVO, La colpa, cit. nota n 34, p. 461 s., 564.

${ }^{36}$ Propone distinguir entre "culpa consciente" (del alcance o de la naturaleza prudencial de la regla de conducta inobservada), "culpa con representación" (de elementos de hecho distintos del resultado) y "culpa con previsión" (del resultado), CANESTRARI, Stefano, Dolo eventuale e colpa cosciente. Ai confini tra dolo e colpa nella struttura delle tipologie delittuose, Milano: Giuffrè, 1999, p. 23 s., 79 s., 202 s., 308 s.

${ }^{37}$ Cfr. p. ej.: HALL, Jerome, "Negligent Behavior should be excluded from Penal Liability", Columbia Law Review, Vol. 63, nº 4 (1963), pp. 632-644, p. 633 s., 641 s.; CENTONZE, La normalità, cit. nota nº 4, p. 283 s.
} 
Polit. crim. Vol. 13, No 26 (Diciembre 2018) Art. 6, pp. 858-903.

[http://www.politicacriminal.cl/Vol_13/n_26/Vol13N26A6.pdf]

la estrategia general de prevención del error -sobre todo cuando el error del profesional esté favorecido por la complejidad de la organización del trabajo en equipo-, ya que este objetivo podría perseguirse de manera más eficaz superando el paradigma de la blame culture, esto es, suprimiendo radicalmente de este contexto las variables amenaza y sanción ${ }^{38}$.

Según argumenta una parte de la doctrina, semejante cambio de paradigma debilitaría las principales razones de la medicina defensiva: el temor a la sanción y la cultura del ocultamiento del error. Esto permitiría detectar las razones fácticas que favorecen su ocurrencia, y fomentar, sobre esta base de conocimiento, el desarrollo de nuevas políticas de prevención y buenas prácticas. Sería aprendiendo de la experiencia registrada, y no a través de la amenaza, que se podrían generar nuevas y mejores estrategias de seguridad y prevención $^{39}$.

Sin embargo, este planteamiento nos pone de cara a otras cuestiones dogmáticas aún sin soluciones de consenso en la doctrina contemporánea. La supresión de los delitos culposos, incluidos los cometidos con culpa consciente, supondría, en efecto, finalmente aclarar la frontera conceptual entre el dolo y la culpa ${ }^{40}$, o bien la adopción de soluciones intermedias, algo así como una tercera forma de culpabilidad ${ }^{41}$. En el caso de querer suprimir sólo la culpa

${ }^{38}$ CAPUTO, Matteo, “Agente modello” e responsabilità per colpa in campo sanitario. Problemi e prospettive, Milano: EDU Catt, 2012, 105 s., 126 s.; RISICATO, L’attività, cit. nota no 10, p. 15 s., 22-3; más prudente frente a la opción de la despenalización, HERNÁNDEZ BASUALTO, “Consentimiento", cit. nota n 27, p. 183-4, según el cual "el camino de la descriminalización de las lesiones culposas inferidas en el contexto de un tratamiento médico no parece un camino transitable (...) por razones elementales de igualdad ante la ley y por la importancia de los bienes jurídicos en juego".

${ }^{39}$ MAGLIO, "Error", cit. nota no 13, p. 360-1. A este propósito, véanse: ROMEO CASABONA, Carlos María; URRUELA MORA, Asier, El establecimiento de un sistema nacional de notificación y registro de eventos adversos en el sector sanitario: aspectos legales, Granada: Comares, 2010; y, en Italia, la propuesta de lege ferenda de FORTI, Gabrio; CATINO, Maurizio; D’ALESSANDRO, Francesco; MAZZUCATO, Claudia; VARRASO, Gianluca, Il problema della medicina difensiva. Una proposta di riforma in materia di responsabilità penale nell'ambito dell'attività sanitaria e gestione del contenzioso legato al rischio clinico, Pisa: ETS, 2010, p. 199 s.

${ }^{40}$ Más allá de la "segunda fórmula de Frank", controvertida en la teoría, y de difícil aplicación en los casos complejos. Véase la nota siguiente.

${ }^{41}$ Solución sugerida por FORNASARI, Gabriele, "Dolo, errore sul fatto ed aberratio ictus", en: VV.AA., Introduzione al sistema penale, Vol. II, Torino: Giappichelli, 2001, pp. 155-197, p. 173, antes que el camino hacia la individuación de una categoría intermedia entre la culpa y el dolo (inexistente en el Derecho positivo italiano) fuera tomado por la propia jurisprudencia italiana, al decidir casos donde la calificación de la clase de responsabilidad (dolosa o culposa) es particularmente compleja, aplicando penas intermedias entre las máximas y mínimas fijadas en abstracto para los delitos culposos y los dolosos, respectivamente. Para una perspectiva detallada sobre este debate, en la discusión italiana: DONINI, Massimo, "Il dolo eventuale: fatto-illecito e colpevolezza", Diritto Penale Contemporaneo - Rivista Trimestrale, no 1 (2014), pp. 70-127, en: http://www.penalecontemporaneo.it/d/2857 [visitado el 12.01.2018]. Sobre los obstáculos que supondría la configuración de una tercera forma de culpabilidad (teniendo en cuenta también la dificultades definitorias y aplicativas surgidas en el Derecho comparado respecto a la recklessness y la mise en danger délibérée de la personne d'autrui), véanse: CANESTRARI, Dolo eventuale, cit. nota $\mathrm{n}^{\circ} 36$, p. 288 s.; MELCHIONDA, Alessandro, "Forme di colpevolezza e prospettive di codificazione europea. Brevi riflessioni sulle auspicate revisioni normative dei confini fra dolo e colpa", en: CADOPPI, Alberto (Ed.), Verso un nuovo codice penale modello per l'Europa. Offensività e colpevolezza, Padova: Cedam, 2002, pp. 185-201. 
PERIN, Andrea. "La redefinición de la culpa (imprudencia) penal médica ante el fenómeno de la medicina defensiva. Bases desde una perspectiva comparada".

inconsciente ${ }^{42}$, deberíamos ser capaces de sostener que siempre merece más reproche quien ha provocado (o no ha evitado, hallándose en posición de garante) un perjuicio penalmente relevante cuando la conducta esté acompañada de un elemento psicológico efectivo -la consciencia de la infracción, o bien la representación o previsión efectiva del resultado, etc., en comparación con quien ni siquiera se ha dado cuenta de haber estado generando (o de no haber estado evitando) un riesgo intolerable. Pero, como se sabe, este aspecto está aún lejos de ser pacífico en la discusión actual.

\section{Reformas recientes en materia de culpa médica: la experiencia italiana}

\subsection{El contexto}

Entre los caminos mencionados, el primero -la limitación de la culpa como criterio de imputación y ámbito de responsabilidad- ya ha sido escogido por el legislador italiano en dos ocasiones, a través de las reformas de 2012 y 2017. Frente a la formulación del art. 43 del Código Penal italiano, que otorga relevancia penal a cualquier infracción del cuidado debido ("cuando el resultado haya sido realizado por negligencia, imprudencia, impericia, o bien, por infracción de leyes, reglamentos, órdenes, disciplinas") sin prever ninguna graduación, esta reformas han sido adoptadas con el objetivo de proporcionar a los jueces criterios de evaluación más precisos, disminuyendo de esta forma el ámbito de discrecionalidad e incertidumbre que favorece la medicina defensiva. En efecto, si bien durante un tiempo los tribunales italianos han acudido al criterio de la "especial dificultad" indicado por el art. 2236 del Código Civil para justificar la limitación de la culpa médica a los casos de culpa grave o temeraria, últimamente, y antes de la reforma del 2012, éste había sido abandonado, lo que se tradujo en un aumento considerable de condenas por mala praxis médica ${ }^{43}$.

En cuanto al contexto doctrinario, el debate de las últimas décadas ha sido protagonizado por dos paradigmas teóricos, los cuales son en buena medida -aunque no del todo, según veremos- alternativos.

Conforme al modelo doctrinal deóntico-objetivo (generalizador), el criterio que nos permitiría precisar el contenido normativo del cuidado debido sería la previsibilidad ex ante del resultado lesivo en concreto $\left(\right.$ hic et nunc) ${ }^{44}$. Este juicio debería llevarse a cabo desde la

\footnotetext{
${ }^{42}$ Sobre la oportunidad de limitar la punibilidad de la culpa inconsciente en una perspectiva de lege ferenda, ver también MELCHIONDA, "Forme di colpevolezza", cit. nota n' 41, p. $185 \mathrm{~s}$.

${ }^{43}$ Sobre estas orientaciones jurisprudenciales, y la relevancia asumida por el art. 2236 del Código Civil italiano en ese contexto, véanse: DI LANDRO, Andrea R., "I criteri di valutazione della colpa penale del medico, dal limite della "gravità" ex art. 2236 c.c. alle prospettive della gross negligence anglosassone", Indice penale (2004), pp. 733-769; MONTANARI VERGALLO, Gianluca, La colpa sanitaria verso la fase del bilanciamento: analisi de iure condito e proposte di riforma, Milano: Giuffrè, 2016, p. 36 s.; MASSARO, Antonella, "L'art. 590-sexies c.p., la colpa per imperizia del medico e la camicia di Nesso dell'art. 2236 c.c.”,

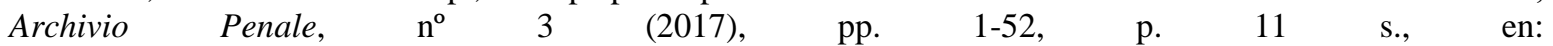
http://www.archiviopenale.it/File/DownloadArticolo?codice=0ccdde58-a33c-4327-824e-

$23 \mathrm{e} 05851 \mathrm{~b} 6 \mathrm{5} \& \mathrm{idarticolo}=15217$ [visitado el 23.04.2018].

${ }^{44}$ En la misma perspectiva se acude también al concepto de "riesgo permitido" (erlaubtes Risiko) para definir culposa o imprudente la conducta que crea un riesgo más allá lo jurídico-penalmente permitido; a esta conducta, dada la necesidad de una "relación de riesgo" entre la infracción y con el resultado, se le podrá imputar ex post
} 
Polit. crim. Vol. 13, No 26 (Diciembre 2018) Art. 6, pp. 858-903.

[http://www.politicacriminal.cl/Vol_13/n_26/Vol13N26A6.pdf]

perspectiva ex ante del parámetro normativo del homo eiusdem condicionis et professionis ${ }^{45}$ (la Maßfigur de la dogmática alemana ${ }^{46}$; el hombre cuidadoso o la persona inteligente y sensata de la doctrina española; the reasonable person, en la tradición de Common Law ${ }^{47}$ ). Es decir, un sujeto imaginario (i.e., ideal-normativo, pero no necesariamente "fiel al Derecho" ${ }^{48}$ ) dotado de los conocimientos y las capacidades que sea preciso exigir objetivamente a los miembros típicos del grupo social o profesional al que pertenezca el autor del hecho. Piénsese, por ejemplo, en un neurocirujano o en un anestesista eiusdem condicionis $^{49}$.

dicho resultado cuando éste represente la realización de dicho riesgo, perteneciendo al ámbito -o fin- de protección de la norma inobservada (y cuando no existan otras razones de interrupción del mismo "nexo de riesgo" -i.e., de imputación objetiva): FORTI, Colpa, cit. nota $\mathrm{n}^{\circ}$ 2, p. 359 s.; en la literatura chilena: CARNEVALI, Raúl, "Un examen a los problemas de relación de causalidad y de imputación objetiva conforme a la doctrina penal chilena", en: VARGAS PINTO, Tatiana (Ed.), La relación de causalidad. Análisis de su relevancia en la responsabilidad civil y penal, Cuadernos de extensión, $\mathrm{N}^{\circ} 15$, Santiago: Universidad de los Andes, 2008, pp. 223-240; VARGAS PINTO, "La imprudencia", cit. nota n 27, p. 112 s., 120; MAÑALICH RAFFO, Juan Pablo, "La imprudencia como estructura de imputación", Revista de Ciencias Penales, Vol. XLII, $\mathrm{n}^{\circ} 3$ (2015), pp. 13-36, p. 24 s., 26 s.

${ }^{45}$ GALLO, Marcello, "Colpa penale (dir. vig.)", Enciclopedia del diritto, Vol. VII, Milano: Giuffrè, 1960, pp. 624-644, p. 640; MARINUCCI, La colpa, cit. nota n 2, p. 194 s.; DE FRANCESCO, Gennaro V., "Sulla misura soggettiva della colpa", Studi Urbinati di scienze giuridiche, politiche ed economiche, Nuova Serie A (197778), pp. 273-343, p. 298 s.; FORTI, Colpa, cit. nota n 2, p. 237 s.

${ }^{46}$ WELZEL, Fahrlässigkeit, cit. nota n ${ }^{\circ}$ 2, p. 15 s.; BURGSTALLER, Das Fahrlässigkeitsdelikt, cit. nota $n^{\circ}$ 34, p. 54 s.

${ }^{47}$ Una buena perspectiva sobre el debate en esa tradición la ofrece BARON, Marcia, "The Standard of the Reasonable Person in the Criminal Law", en: DUFF, R.A.; FARMER, Lindsay; MARSHALL, S.E., RENZO, Massimo; TADROS, Victor (Eds.), The Structures of the Criminal Law, Oxford: Oxford University Press, 2012, pp. 1-30.

${ }^{48}$ La precisión de la norma de cuidado requiere proporcionar al intérprete criterios social y teleológicamente válidos, sin necesidad de acudir a parámetros simbólicos (de matriz funcionalista, y necesariamente generalizadores) desprovistos de un poder normativo efectivo. Puedo ser el ciudadano más prudente y responsable del mundo (en el sentido ético de la palabra "responsable"), y aun así ser totalmente indiferente frente a las expectativas del derecho (en todos sus "formantes": derecho positivo, derecho sapiencial, jurisprudencia) y, por ende, a la posible antijuridicidad de mi conducta.

${ }_{49}$ Algunos autores, a partir del rechazo de las antiguas teorías del "hombre abstracto pro-medio" y del "buen padre de familia", han defendido la adopción de un baremo individualizador: entre otros, STRATENWERTH, Günther, "L'individualizzazione della misura di diligenza nel delitto colposo", Rivista italiana di diritto e procedura penale, Vol. 29, n 3 (1986), pp. 635-652; ZUGALDÍA ESPINAR, José Miguel, "La infracción del deber individual de cuidado en el sistema del delito culposo", Anuario de Derecho Penal y Ciencias Penales, Vol. 2 (1984), pp. 321-332; en Chile: VAN WEEZEL, Alex, "Parámetros para el enjuiciamiento de la infracción al deber de cuidado en los delitos imprudentes", Revista Chilena de Derecho, Vol. 26, nº 2 (1999), pp. 323-336, p. 332 s.; REYES ROMERO, Ítalo, "Sobre la construcción de la exigencia de cuidado", Política Criminal, Vol. 10, no 19 (2015), pp. 56-91, p. 73 s., 82 s., en: http://www.politicacriminal.cl/Vol_10/n_19/Vol10N19A3.pdf. Sin embargo, en mi opinión, esta doctrina acaba defendiendo soluciones en realidad homogéneas a la teoría generalizadora del parámetro objetivo diferenciado según el tipo de actividad o contexto social -en este sentido, homo eiusdem condicionis et professionis-. En efecto, como observa MAÑALICH RAFFO, "La imprudencia", cit. nota $\mathrm{n}^{\circ} 44$, p. 22-3, "la exigencia o incumbencia de cuidado ha de encontrarse objetivamente determinada, en atención a cual sea la expectativa de precaución puesta sobre una persona que se desenvuelva en el correspondiente contexto, lo cual ciertamente puede ser relativo al desempeño de un determinado rol" (sin perjuicio de que se defienda además, por parte del mismo autor, que la imputación por imprudencia requiere en seguida considerar también "las capacidades y los conocimientos de los cuales dispusiera efectivamente el sujeto (pasivo) de la imputación"). Más allá de otras críticas que se pueden formular, la explicación de esto se encuentra, básicamente, en la bien conocida imposibilidad lógica de juzgar según el parámetro o las 
PERIN, Andrea. "La redefinición de la culpa (imprudencia) penal médica ante el fenómeno de la medicina defensiva. Bases desde una perspectiva comparada".

Sin embargo, los límites de este paradigma son bien conocidos. Entre éstos cabe destacar: (1) la indeterminación intrínseca del parámetro normativo ${ }^{50} \mathrm{y}$, por ende, la tendencia de los tribunales a objetivizar los juicios de imputación, a menudo afectados por hindsight bias (algo que, como muestran algunos estudios, sucede con mayor frecuencia en la jurisprudencia en materia de responsabilidad médica ${ }^{51}$ ), lo que deriva en el diseño de parámetros objetivos excesivos en términos de exigibilidad ${ }^{52}$; (2) la indeterminación del propio "resultado" como objeto del juicio de previsibilidad ex ante, cuya inevitable redescripción (i.e., normativización) puede llevar, a su vez, a una expansión ilimitada del alcance de la responsabilidad de los médicos ${ }^{53}$.

características del propio sujeto que se juzga, lo que supone aceptar, por individualizador que sea el planteamiento defendido, de todos modos, algún corte normativo (alguna generalización). En cualquier caso, sobre la superación definitiva de las viejas concepciones del "hombre promedio" por la teoría del parámetro generalizador (pero diferenciado según el tipo de actividad, contexto y grupo social), véanse las obras citadas supra, nota $\mathrm{n}^{\mathrm{o}} 45$.

En cuanto, además, al largo debate acerca de la relevancia de los conocimientos nomológicos y/o las capacidades especiales, esto refleja en mi opinión algunos malentendidos y no tiene por ello toda la importancia que se le suele otorgar. Cualquier conocimiento o capacidad especial (piénsese, p. ej., en los médicos especialistas que, habiendo realizado ciertos estudios como miembros de un equipo de investigación, saben que el fármaco X tiene ciertas características que suponen ciertas ventajas terapéuticas -conocidas-, aunque también ciertos riesgos desconocidos por la generalidad de los médicos hospitalarios), permite definir un estándar, y por ello un parámetro de diligencia (aplicable a dichos especialistas). La adopción de un parámetro generalizador, pero diferenciado, lleva necesariamente a esta solución. Véanse, con matices diferentes: MARINUCCI, La colpa, cit. nota $\mathrm{n}^{\circ}$ 2, p. 196; CASTRONUOVO, La colpa, cit. nota $\mathrm{n}^{\circ}$ 34, p. 456 s.; con especial referencia a la responsabilidad médica: ROMEO CASABONA, El médico (t. II), cit. nota n 11, p. 264 s., 267; GÓMEZ RIVERO, Maria del Carmen, La responsabilidad penal del médico, Valencia: Tirant lo Blanch, 2008, p. 382 s. En un sentido parecido, asumiendo sin embargo una perspectiva individualizadora, ROSAS OLIVA, "La delimitación", cit. nota ${ }^{\circ} 8$, p. 10. Y esto confirma cuán relativa es la importancia de este debate. En cambio, sobre la relación dogmática entre el principio de confianza y el estándar objetivo (generalizador y diferenciado), y más referencias al respecto: FORTI, Colpa, cit. nota nº 2, p. 269-71, 274 s.; PERIN, "La condotta", cit. nota $\mathrm{n}^{\circ} 7$, p. $226 \mathrm{~s}$.

${ }^{50}$ Con especial referencia a la responsabilidad médica: MICHELETTI, Dario, "La normatività della colpa medica nella giurisprudenza della Cassazione", en: CANESTRARI, Stefano; GIUNTA, Fausto; GUERRINI, Roberto; PADOVANI, Tullio (Eds.), Medicina e diritto penale, Pisa: Edizioni ETS, 2009, pp. 247-283; VALBONESI, Cecilia, "Linee guida e protocolli per una nuova tipicità dell'illecito colposo", Rivista italiana di diritto e procedura penale, Vol. 56, $\mathrm{n}^{\circ} 1$ (2013), pp. 250-301; en Chile, VARGAS PINTO, "La imprudencia", cit. nota $\mathrm{n}^{\circ} 27$, p. 105 s. Más favorable a la Maßfigur, CAPUTO, "Agente modello, cit. nota no 38, p. 21 s.

${ }^{51}$ Se suele acudir el concepto de hindsight bias (o "prejuicio de perspectiva") para indicar un sesgo cognitivo que, en este contexto, fomenta la tendencia de los tribunales a considerar a posteriori (en el momento del juicio) algo ya sucedido (el resultado lesivo) como más previsible de lo que fue efectivamente ex ante (esto es, sin conocimiento de lo sucedido). Ver. p. ej., PETERS, Philip G. Jr., "The Role of Jury in Modern Malpractice Law", Iowa Law Review, Vol. 87 (2002), pp. 909-970, en: https://ssrn.com/abstract=310681 [visitado el 12.01.2018]; HASKEL, Michael A., "A proposal for addressing the effects of hindsight and positive outcome biases in medical malpractice cases", Tort Trial \& Insurance Practice Law Journal, Vol. 42, n 3 (2007), pp. 895-940, en: https://www.jstor.org/stable/25763860?seq=1\#page_scan_tab_contents [visitado el 12.01.2018]; OEBERST, Aileen; GOECKENJAN, Ingke, "When being wise after the event results in injustice: Evidence for hindsight bias in judges' negligence assessments", Psychology, Public Policy, and Law, Vol. 22, no 3 (2016), 271-279, en: http://psycnet.apa.org/doiLanding?doi=10.1037\%2Flaw0000091 [visitado el 12.01.2018].

${ }_{52}^{5}$ P. ej., VAN WEEZEL, "Parámetros", cit. nota no 49, p. 326.

${ }^{53}$ En materia de responsabilidad médica, este problema se ha planteado sobre todo ante hipótesis de responsabilidad del medico psiquiatra por el suicidio o por actos violentos y delictivos cometidos por el paciente. ¿Cuál es el objeto del juicio de previsibilidad ex ante? ¿el resultado hic et nunc, o el tipo o categoría 
Debido a lo anterior, otros autores defienden la necesidad de limitar el alcance de la culpa penal a las infracciones de las pautas de conducta positiva o socialmente predeterminadas ("usos", protocolos médicos, reglamentos, etc.). Este modelo, de tipo "praxeológicopositivistico", según defienden sus partidarios ${ }^{54}$, supondría un enfoque más garantizador, pues ya no se trataría de precisar el contenido normativo del deber de cuidado acudiendo a un parámetro normativo imaginario, sino a través de pautas de conducta ya reconocidas y adoptadas por el cuerpo social o en el ámbito profesional de que se trate.

Sin embargo, también este planteamiento presenta ciertos límites. En efecto, si bien es cierto que a menudo los profesionales pueden acudir a pautas de actuación predeterminadas frente a casos típicos $^{55}$, en otras circunstancias dichos protocolos no se ajustan al deber de cuidado objetivamente exigible, y por ello se requiere "un alejamiento de la lex artis generalmente aceptada (...), y recurrir al criterio de lo que haría un profesional prudente en una situación semejante" 56 . En efecto, no siempre los profesionales pueden acudir a pautas de conducta predeterminadas. Y esto, en general, se explica por los siguientes factores: (1) porque existen casos clínicos atípicos, que exigen recurrir a medidas de intervención asimismo "atípicas"57; (2) por las características intrínsecas de la medicina como técnica basada en conocimientos en constante evolución (y a menudo controvertidos); (3) por la necesidad de reconocer ciertos márgenes para la libertad de método y de tratamiento, siempre que se respete la voluntad del paciente $^{58}$. De allí la necesidad de volver a preguntarse, de cara a eventos adversos, qué hubiese hecho un médico sensato y prudente en una situación semejante.

Debido a lo anterior, además, es evidente que el apego acrítico a los protocolos podría representar un tipo particular de medicina defensiva "negativa", pues supondría no acudir al ser necesario- a estándares terapéuticos más avanzados y eficaces, aunque no formalizados o "codificados", lo que no reflejaría una actitud orientada al mejor resultado para el

de resultado? Ver, p. ej., CUPELLI, Cristiano, "La colpa dello psichiatra. Rischi e responsabilità tra poteri impeditivi, regole cautelari e linee guida", Diritto Penale Contemporaneo (2016), pp. 1-21, p. 18 s., en: https://www.penalecontemporaneo.it/upload/1458553545CUPELLI_2016a.pdf [visitado el 12.01.2018]; más referencias en PERIN, "La condotta", cit. nota n' 7, p. 212, nota 22.

${ }^{54}$ En general, véase por todos: GIUNTA, Fausto, "La normatività della colpa. Lineamenti di una teorica", Rivista italiana di diritto e procedura penale, Vol. 42 (1999), pp. 86-115; en materia de culpa médica: MICHELETTI, "La normatività", cit. nota nº 50; VALBONESI, "Linee guida”, cit. nota no 50.

${ }^{55}$ ROMEO CASABONA, El médico (t. II), cit. nota no 11, p. 269.

56 JORGE-BARREIRO, Agustín, “Aspectos básicos de la imprudencia punible en la actividad médicoquirúrgica”, Estudios Penales y Criminológicos, no 14 (1989-90), pp. 138-175, p. 151; RUEDA MARTÍN, M. Ángeles, "La concreción del deber objetivo de cuidado en el desarrollo de la actividad médico-quirúrgica curativa", InDret Penal, Núm. 4 (2009), pp. 1-58, p. 48 s., en: http://www.indret.com/pdf/672.pdf [visitado el 12.01.2018]; en sentido parecido, VARGAS PINTO, "La imprudencia", cit. nota n 27, p. 114, 117. En general, a propósito de la necesidad, en ciertas circunstancias, de ir más allá de lo usual y la costumbre, TORÍO LÓPEZ, Ángel, "El deber objetivo de cuidado en los delitos culposos", Anuario de Derecho Penal y Ciencias Penales (1974), pp. 25-59, p. 29.

${ }^{57}$ PERIN, "La condotta", cit. nota n 7, p. 223-6 (y más referencias en la nota 75).

${ }^{58}$ Cfr. SILVA SÁNCHEZ, Jesús María, Medicinas alternativas e imprudencia médica, Barcelona: Bosch, 1999, p. 45 s.; ROMEO CASABONA, El médico (t. II), cit. nota nº 11, p. 269 s. 
PERIN, Andrea. "La redefinición de la culpa (imprudencia) penal médica ante el fenómeno de la medicina defensiva. Bases desde una perspectiva comparada".

paciente $^{59}$

Este debate doctrinario ha desembocado también en la publicación de importantes estudios monográficos sobre la materia ${ }^{60}$ y en la discusión de proyectos de lege ferenda, como la propuesta presentada por el Centro Studi "Federico Stella" de la Università Cattolica Sacro Cuore de Milán (2010) ${ }^{61}$.

\subsection{La reforma Balduzzi (2012)}

De cara a esta situación, el legislador italiano intervino por primera vez a través de la Ley núm. 189 de 8 de noviembre de 2012, con la finalidad de buscar una solución de equilibrio, frente al cambio de orientación de la jurisprudencia y a las quejas de la clase médica, para afrontar el problema de la medicina defensiva.

Esta reforma se proyecta sobre dos ejes principales: (1) reconocer la relevancia central de los protocolos y las guidelines en la regulación de la actividad sanitaria y, por ende, en la precisión del contenido normativo del deber de cuidado del facultativo; (2) exigir, al menos en algunos casos (ya veremos cuáles), la culpa grave del profesional, excluyendo la relevancia penal de los supuestos de culpa leve (o simple).

En este sentido, el art. 3, inc. 1, de la Ley citada establece lo siguiente:

"El profesional sanitario que, en el ejercicio de su actividad, cumpla con las guías y las buenas prácticas acreditadas por la comunidad científica, no será penalmente responsable por culpa leve" 62 .

Cabe decir que esta disposición no destaca precisamente por su claridad ${ }^{63}$. Sin embargo, tampoco es correcto sostener, como hicieron algunos en un primer momento, que su formulación contendría una contradicción patente, dada por la previsión de que un facultativo podría actuar de forma culposa aun cumpliendo con las guidelines.

\footnotetext{
${ }^{59}$ ROIATI, Alessandro, Medicina difensiva e colpa professionale medica in diritto penale. Tra teoria e prassi giurisprudenziale, Milano: Giuffrè, 2012, p. 140 s.; RISICATO, L'attività, cit. nota nº 10, p. 26.

${ }^{60}$ ROIATI, Medicina difensiva, cit. nota $n^{\circ}$ 59; MANNA, Adelmo, Medicina difensiva e diritto penale. Tra legalità e tutela della salute, Pisa: Pisa University Press, 2014.

${ }^{61}$ FORTI; CATINO; D'ALESSANDRO; MAZZUCATO; VARRASO, Il problema, cit. nota no 39 . Ver infra, notas $\mathrm{n}^{\circ} 117$ y 124 .

${ }^{62}$ Trad. propia del texto original: "L'esercente le professioni sanitarie che nello svolgimento della propria attività si attiene a linee guida e buone pratiche accreditate dalla comunità scientifica non risponde penalmente per colpa lieve".

${ }^{63}$ Véanse sobre la reforma: PULITANÒ, Domenico, "Responsabilità medica: letture e valutazioni divergenti del novum legislativo", Diritto Penale Contemporaneo - Rivista Trimestrale, ${ }^{\circ} 4$ (2013), pp. 73-85, en: https://www.penalecontemporaneo.it/d/2269 [visitado el 12.01.2018]; GIUNTA, Fausto, "Protocolli medici e colpa penale secondo il «decreto Balduzzi»", Rivista italiana di medicina legale, Vol. 35, n 2 (2013), pp. 819832; VALLINI, Antonio, "L'art. 3 del "Decreto Balduzzi" tra retaggi dottrinali, esigenze concrete, approssimazioni testuali, dubbi di costituzionalità", Rivista italiana di medicina legale, Vol. XXXV, $\mathrm{n}^{\circ} 2$ (2013), pp. 736-750; DI GIOVINE, Ombretta, "In difesa del c.d. decreto Balduzzi (ovvero: perché non è possibile ragionare di medicina come se fosse diritto e di diritto come se fosse matematica)", Archivio penale, $\mathrm{n}^{\circ} 1$ (2014), pp. 1-23; MONTANARI VERGALLO, La colpa, cit. nota $\mathrm{n}^{\circ}$ 43, p. $73 \mathrm{~s}$.
} 
En efecto, de esta manera la reforma asumía un criterio ya indicado en los apartados anteriores (destacando los límites del modelo "praxeológico"), a saber, que es posible que un facultativo adopte, aplique o cumpla con best practices, guidelines, protocolos, etc., y actúe, no obstante, de forma inadecuada, esto es, incumpliendo el deber de cuidado. Dicho de otra manera: el simple hecho de haber actuado conforme a ciertas leges artis no significa excluir de por sí que la conducta del profesional pueda ser juzgada culposa respecto al resultado lesivo que haya provocado (o no haya evitado, cuando se trate de supuesta responsabilidad por omisión impropia).

Pero, ¿cuándo puede darse esta circunstancia?

En primer lugar, cuando la lex artis adoptada no indica el deber de cuidado adecuado para el caso concreto, por la simple razón que no procede aplicarla bajo ciertas condiciones (esto es, no es pertinente respecto al caso clínico). Es decir, el médico incumple el deber de cuidado por aplicar un protocolo fuera de su ámbito de aplicación. Y ello puede suceder: (1) por un error de apreciación acerca de las circunstancias concretas que definen la ocasión de adoptar ciertas normas de conducta; (2) o bien, por un error de elección de la lex artis aplicable (pese a una correcta apreciación de la naturaleza del caso clínico).

En segundo lugar, el cumplimiento del protocolo no excluye la negligencia del facultativo cuando, pese a que la lex artis predeterminada y reconocida o incluida en fuentes técnicas sea pertinente respecto al caso clínico, el cumplimiento del deber de cuidado requiera ir más allá, y adoptar medidas distintas respecto de aquellas generalmente adoptadas frente a casos similares. Esto puede ser necesario cuando la pauta adoptada se revele obsoleta de cara a la evolución del conocimiento científico que heterointegra el contenido de las leges artis médicas.

Entre las hipótesis pertenecientes a este segundo grupo (lex artis pertinente, pero inadecuada), los casos menos problemáticos son aquellos en los cuales los peritajes a disposición del juez indican de forma coherente y consensuada la conducta que el facultativo habría tenido que realizar en las condiciones dadas, esto es, conforme a los conocimientos disponibles y aceptados por la comunidad científica en un momento dado. Se trata de casos en los cuales, pese a que el deber de cuidado no está formalizado, la comunidad científica está en condiciones de expresar, sin incertidumbres relevantes, la existencia de una manera correcta y adecuada de hacer frente a ciertas condiciones clínicas o de realizar pruebas para la realización de ciertas terapias, etc. La lex artis no se corresponde a las prácticas generalmente adoptadas (a la costumbre). Aun así, la comunidad científica puede acreditar, en un momento dado, su existencia y validez general ${ }^{64}$.

\footnotetext{
${ }^{64}$ Un ejemplo llamativo y paradigmático en este sentido es el caso ocurrido en España a finales de los ochenta, cuando, no obstante la disponibilidad de técnicas más avanzadas y ya adoptadas por algunos hospitales españoles para detectar la presencia del VIH en las muestras de sangre para las transfusiones, en la unidad de hematología de un hospital catalán se siguió aplicando el protocolo (la lex artis formalizada) que sólo imponía excluir de los donantes todos los sujetos pertenecientes a ciertos "grupos de riesgo" (homosexuales, prostitutas, etc.), sin realizar otros tipos de prueba. Cfr., sobre este caso, CÓRDOBA RODA, Joan, “Configuración de la
} 
PERIN, Andrea. "La redefinición de la culpa (imprudencia) penal médica ante el fenómeno de la medicina defensiva. Bases desde una perspectiva comparada".

Más complejos son, en cambio, los casos en los cuales la validez de la lex artis efectivamente adoptada - pero que no responde al deber de cuidado- resulte al menos controvertida ${ }^{65}$. Esto puede suceder con mayor frecuencia respecto de las llamadas reglas de cuidado "impropias", es decir, aquellas que no aseguran evitar la realización del riesgo perteneciente a su ámbito de protección ${ }^{66}$ (esto es, no aseguran el éxito del tratamiento). En estos casos, la lex artis adoptada puede ser adecuada (i.e., conforme a los conocimientos disponibles y acreditados por la comunidad científica), pero a partir del fracaso del tratamiento puede surgir la cuestión de si realmente era la mejor opción o una de las mejores opciones disponibles.

De todos modos, el límite de la culpa grave previsto por la reforma Balduzzi encontraba aplicación precisamente cuando el cumplimiento del deber de cuidado requería un alejamiento de la lex artis generalmente aceptada en el caso concreto, siendo por ello necesario recurrir nuevamente al criterio de lo que haría el profesional sensato y prudente en una situación semejante ${ }^{67}$. Su ratio fue entonces reconocer, a través de la no punibilidad de la culpa leve, la especial dificultad asociada a la necesidad de adoptar una norma de conducta no usual en aquellas situaciones en las cuales ya existía una regla de referencia en la cual el facultativo debería, al menos en principio, haber podido confiar. En fin: se trataba de valorar a favor del facultativo la mayor dificultad, pese a su exigibilidad objetiva, de ir más allá de los protocolos y la costumbre ${ }^{68}$.

En este sentido, la solución adoptada por esta reforma parecía indicar -en mi opinión- un camino razonable y equilibrado ${ }^{69}$, porque suponía fijar criterios (de actuación, en el caso de los médicos; de juicio en el caso de los tribunales) orientados a limitar el problema de la medicina defensiva. (1) En primer lugar, se formalizaba el criterio según el cual no siempre el facultativo puede gozar del amparo del protocolo. Esto se estableció mediante la indicación al médico en orden a evaluar de forma crítica y autónoma la adecuación de la lex artis; evaluación no sólo referida a su aplicabilidad al caso clínico, sino también a su contenido intrínseco, evitando caer de este modo en automatismos. Esto último debido al hecho que la decisión del médico de actuar sin mayores cuestionamientos conforme al protocolo puede no coincidir con el interés del paciente. (2) Sin embargo -y aquí está el elemento de equilibrio, cuando el médico incumpliese el cuidado debido por cumplir una lex artis (pertinente

\footnotetext{
imprudencia en el ámbito sanitario en el nuevo Código penal", Derecho y Salud, Vol. 4, no 2 (1996), pp. 141146, p. 143 s.; SILVA SÁNCHEZ, Medicinas, cit. nota nº 58, p. 29 s.; ROMEO CASABONA, Carlos María, "Evolución del tratamiento jurídico-penal de la imprudencia del personal médico-sanitario", Revista Jurídica de Castilla y León, $\mathrm{n}^{\circ} 13$ (2007), pp. 211-251, p. 230 s.; PERIN, "La condotta", cit. nota nº 7, p. 216-7.

${ }^{65}$ Véase, por ejemplo, la Resolución no 68380 de la Corte Suprema chilena, Sala Segunda (Penal) de 22 de agosto de 2012. Causa n ${ }^{\circ} 3240 / 2012$.

${ }^{66}$ VENEZIANI, Paolo, Regole cautelari "proprie" ed "improprie" nella prospettiva delle fattispecie colpose causalmente orientate, Padova: Cedam, 2003, p. 15 s.

${ }^{67}$ En efecto, de estas hipótesis de "concurso de normas" (praxis vs. regla de cuidado exigible en el caso concreto), hay que excluir aquellas que en doctrina han sido denominadas de concurso "aparente" y "cumulativo", es decir, aquellas en las cuales "el alcance preventivo de la regla "codificada" (...) no es congruente respecto del riesgo concreto y específico", y aquellas en las cuales no se haya cumplido la prudencia o diligencia necesaria a la hora de aplicar la norma de pericia predeterminada: así, VALLINI, "L'art. 3", cit. nota ${ }^{\circ} 63$, p. 744 s. (trad. propia).

${ }^{68}$ De forma semejante, VALLINI, “L'art. 3", cit. nota $n^{\circ}$ 63, p. 746-7.

${ }^{69}$ En defensa de la muy criticada reforma de 2012, también DI GIOVINE, "In difesa”, cit. nota no 63, p. 2 s.
} 
respecto al caso clínico, pero inadecuada de por sí), había que tener en cuenta las mayores dificultades que supone y lleva consigo la necesidad de alejarse de una práctica asumida y consolidada. De esta forma, se nos sugería también un posible criterio de gravedad, idóneo a su vez para limitar el alcance de la intervención penal de forma razonable, y disminuir aquel temor a la sanción que, como hemos visto, fomenta la medicina defensiva ${ }^{70}$.

Los mayores límites destacados por la doctrina son, en cambio, los siguientes ${ }^{71}$. (1) No se indicaban criterios para determinar cuáles protocolos o guidelines $-\mathrm{u}$ otras leges artis formalizadas- pueden servir de parámetro de actuación para los médicos $\mathrm{y}$, de forma correspondiente, de juicio para los tribunales. (2) No definía - o no indicaba criterios para definir judicialmente- el concepto de colpa grave ${ }^{72}$. (3) La aplicación de un régimen favorable sólo a la culpa profesional médica. En todos los demás casos sería aplicable el régimen general del art. 43 del Código penal italiano, que no requiere -como no lo hace expresamente el art. 491 del Código Penal chileno- la culpa grave del profesional ${ }^{73}$. (4) Finalmente, tampoco pareció coherente la limitación de la responsabilidad por culpa grave sólo a los casos en los cuales el profesional erróneamente cumpliera con guidelines, protocolos o buenas prácticas, sin advertir la necesidad de alejarse de las indicaciones proporcionadas por esas fuentes, ya que la misma dificultad también podría subsistir a la hora de actuar sin el auxilio u orientación de reglas modales predeterminadas. En efecto, pese a la creciente formalización, ningún ámbito de la medicina está dominado por avances científicos definitivos. Y, por ello, en muchos casos no contamos con evidencias sobre cuya base establecer guidelines plenamente confiables o aceptadas de forma unánime ${ }^{74}$. Además, hay que tener en cuenta los límites del poder normativo de dichas guidelines, pudiendo consistir en indicaciones demasiado genéricas y elásticas, inidóneas para otorgar pautas de conducta claras y precisas a beneficio de los profesionales ${ }^{75}$.

\subsection{La reforma Gelli-Bianco (2017)}

De cara a estas cuestiones, y con la declarada finalidad de solucionarlas, se aprobó la Ley núm. 24 de 2017, que prevé la derogación de la normativa anterior e introduce, a través de su art. 6, el nuevo art. 590 sexies al Código Penal italiano:

\footnotetext{
70 Trataré de definir este criterio, infra, en el acápite 7.

${ }^{71}$ Véase, para otra síntesis, CUPELLI, Cristiano, "Lo statuto penale della colpa medica e le incerte novità della legge Gelli-Bianco", Diritto Penale Contemporaneo, $\mathrm{n}^{\circ} 4$ (2017), pp. 200-216, p. 214-5. En: https://www.penalecontemporaneo.it/pdf-viewer/?file=\%2Ffoto\%2FDPC_Riv_Trim_4_17.pdf\#page=211 [visitado el 14.06.2018].

${ }^{72}$ CUPELLI, "Lo statuto", cit. nota $\mathrm{n}^{\mathrm{o}}$ 71, p. 202. En cuanto a esta segunda cuestión, sin embargo, me permito discrepar, pues si bien es cierto que no se nos proporciona ninguna definición, como ya he indicado, de la ratio de la disposición parece posible desprender algunos criterios orientativos, como veremos mejor en las conclusiones de este trabajo, en la $\S 7$.

${ }^{73}$ Véanse los acápites 6 y 7.

${ }^{74}$ En sentido semejante, VALLINI, “L'art. 3”, cit. nota no 63, p. 741.

${ }^{75}$ A este propósito, DI LANDRO, Andrea R., Dalle linee guida e dai protocolli all'individualizzazione della colpa penale nel settore sanitario. Misura oggettiva e soggettiva della malpractice, Torino: Giappichelli, 2012, p. $177 \mathrm{~s}$.
} 
PERIN, Andrea. "La redefinición de la culpa (imprudencia) penal médica ante el fenómeno de la medicina defensiva. Bases desde una perspectiva comparada".

\begin{abstract}
"Cuando el resultado se haya realizado por impericia, la punibilidad queda excluida si se han cumplido las recomendaciones previstas por las guías definidas y publicadas conforme a la ley [art. 5 de la Ley 24/2017] o, en su defecto, por las buenas prácticas clínicas, siempre que las recomendaciones contenidas en dichas guías resulten adecuadas al caso concreto" $" 76$.
\end{abstract}

Respecto al modelo anterior, esta reforma prevé las siguientes novedades: (1) se suprime la graduación de la culpa, previendo en su lugar un régimen de no punibilidad (o de atipicidad) aplicable a aquellas conductas que, aun cumpliendo protocolos o buenas prácticas, hayan sido imperitas (art. 6); (2) además, se prevén requisitos legales para identificar los protocolos y las guidelines que puedan heterointegrar o complementar el contenido normativo del deber de cuidado del médico (art. 5).

Centrémonos en el primer aspecto. Cuando la elección de la lex artis había sido pertinente respecto al caso clínico y, sin embargo, el facultativo hubiese tenido que alejarse de la misma, la reforma de 2012 seguía sancionando la culpa grave, mientras que conforme a la regulación vigente la punibilidad quedaría directamente excluida, siempre que las guidelines adoptadas hayan sido definidas y publicadas conforme a la ley (o, en su defecto, hayan sido adoptadas las buenas prácticas clínicas). Asumiendo que esta interpretación sea razonable, el cambio parece muy significativo, pues mientras antes el apego ciego al protocolo no eximía al médico de su responsabilidad (en caso de culpa grave en la elección de la lex artis), ahora el médico promedio eiusdem condicionis supuesto por el legislador no tiene que preocuparse por la adecuación en sí de la pauta aplicada, sino simplemente asegurarse que esté acreditada.

Estamos hablando, por lo tanto, de un modelo regulativo extremadamente defensivista, y por ello mucho menos equilibrado que el anterior.

Además, graves problemas interpretativos han surgido respecto a los supuestos de error ejecutivo ( $\sin$ error in eligendo). En una ocasión, la Corte de Casación ha sostenido que, toda vez que la lex artis elegida resulte pertinente al caso concreto, quedaría excluida la punibilidad de cualquier error ejecutivo, por grave que sea, identificando precisamente en el supuesto de imperita aplicación o ejecución de la lex artis el ámbito de aplicación de la causa

\footnotetext{
${ }^{76}$ Trad. propia del texto original: “qualora l'evento si è verificato a causa di imperizia, la punibilità è esclusa quando sono rispettate le raccomandazioni previste dalle linee guida come definite e pubblicate ai sensi di legge ovvero, in mancanza di queste, le buone pratiche clinico assistenziali, sempre che le raccomandazioni previste dalle predette linee guida risultino adeguate alle specificità del caso concreto" (art. 590 sexies, Código Penal italiano). Sobre esta disposición, con más referencias, además de las aquí citadas: IADECOLA, Gianfranco, "Qualche riflessione sulla nuova disciplina per colpa medica per imperizia nella Legge 8 marzo 2017 N. 24 (Legge cd. Gelli-Bianco)", Diritto Penale Contemporaneo, $\mathrm{n}^{\circ} 6$ (2017), pp. 53-66, p. 57 s., en: https://www.penalecontemporaneo.it/upload/9522-iadecola617.pdf [visitado el 12.01.2018]; MASSARO, Antonella, "L'art. 590-sexies c.p.", cit. nota n 43, p. 39 s.; VALLINI, Antonio, "Linee guida e colpa medica nel quadro teorico del "concorso di regole cautelari". Un'interpretazione teleologica, e conforme alla lettera, dell'art. 590 sexies CP", Legislazione penale (2017), pp. 1-30, en: http://www.lalegislazionepenale.eu/wpcontent/uploads/2017/12/Antonio-Vallini-Linee-guida-e-colpa-medica-Approfondimenti-def..pdf [visitado el 23.04.2018].
} 
Polít. crim. Vol. 13, No 26 (Diciembre 2018) Art. 6, pp. 858-903.

[http://www.politicacriminal.cl/Vol_13/n_26/Vol13N26A6.pdf]

de no punibilidad (rectius, atipicidad) prevista por el citado art. 590-sexies ${ }^{77}$. Sin embargo, también hay sentencias en sentido contrario, que consideran que la primera interpretación traería consigo consecuencias inaceptables, a saber: (a) se generaría un vacío de protección respecto del derecho a la salud (reconocido por el art. 32 de la Constitución italiana) y los bienes jurídicos a él asociados (vida e integridad psicofísica); (b) se plantearían serias cuestiones de legitimidad constitucional desde el punto de vista del principio de igualdad, pues la profesión médica resultaría mucho más protegida que otras. Además, (c) dicha orientación resultaría cuestionable ya desde un punto de vista estrictamente interpretativo del texto legal, pues el concepto de "cumplimiento" debería incluir también la correcta aplicación del protocolo, y no sólo su correcta elección ${ }^{78}$.

Estas dificultades interpretativas llevaron a la intervención del Pleno de la Corte di Cassazione $^{79}$, cuya definición del ámbito de aplicación de la reforma Gelli-Bianco se puede resumir de la siguiente forma ${ }^{80}$ :

a) No procede aplicar la causa de no punibilidad cuando se trate de imprudencia o negligencia.

b) En cuanto a los supuestos de impericia, hay que distinguir:

b1) cuando se trate de error en la elección de la lex artis y debido a la adopción de una lex artis no pertinente respecto al caso clínico, no procederá aplicar la causa de no punibilidad;

b2) cuando se trate de error ejecutivo, y no existan guidelines o buenas prácticas aplicables al caso clínico, tampoco procederá aplicar la causa de no punibilidad;

b3) en cambio, el facultativo será responsable sólo por impericia grave cuando haya cometido un error ejecutivo en la aplicación de una guía o una buena práctica correctamente elegida, es decir, adecuada y pertinente al caso clínico.

Sin querer ir más allá del objetivo de esta contribución, permítasenos observar que la solución adoptada por el Pleno de la Corte está muy lejos de solucionar los graves problemas interpretativos y aplicativos generados por esta reforma. Es más, me atrevo a decir que los agrava.

\footnotetext{
${ }^{77}$ En este sentido se ha pronunciado la Corte di Cassazione en el caso Cavazza: Casación Penal, Sección IV, 19 octubre 2017 - 31 octubre 2017, no 50078. En: https://www.penalecontemporaneo.it/upload/4604cass5007817.pdf [visitado el 12.01.2018]. Esta interpretación parece coherente con la opinión doctrinal según la cual también los supuestos de error ejecutivo merecían el trato sancionador más favorable ya bajo la regulación de 2012 (exclusión de la culpa leve): ver GIUNTA, "Protocolli", cit. nota nº 63, p. 829 s.

${ }^{78}$ Ver IADECOLA, "Qualche riflessione", cit. nota $\mathrm{n}^{\circ} 76, \mathrm{p}$. 59. Acerca de este conflicto jurisprudencial, y para más referencias, BRUSCO, Carlo, "Cassazione e responsabilità penale del medico. Tipicità e determinatezza del nuovo art. 590 sexies c.p.", Diritto Penale Contemporaneo, no 11 (2017), pp. 205-223, p. 205 s., 211, en: https://www.penalecontemporaneo.it/upload/6599-brusco1117.pdf [visitado el 12.01.2018].

${ }^{79}$ Cass., SS.UU., Sent. de 21 de diciembre de 2017, Pres. Canzio, Rel. Vessichelli, Ric. Mariotti.

${ }^{80}$ De forma semejante, CUPELLI, Cristiano, "La legge Gelli-Bianco nell'interpretazione delle Sezioni Unite", Diritto Penale Contemporaneo, $\mathrm{n}^{\mathrm{o}} 12$ (2017), pp. 135-138, p. 136, en: https://www.penalecontemporaneo.it/pdf-viewer/?file=\%2Fpdf-fascicoli\%2FDPC_12_2017.pdf\#page $=135$ [visitado el 12.01.2018]; ID., "L'art. 590-sexies c.p. nelle motivazioni delle Sezioni Unite: un'interpretazione 'costituzionalmente conforme' dell'imperizia medica (ancora) punibile", Diritto Penale Contemporaneo, $\mathrm{n}^{\circ} 3$ (2018), pp. 246-258, en: https://www.penalecontemporaneo.it/pdf-viewer/?file=\%2Fpdffascicoli\%2FDPC_3_2018.pdf\#page=246 [visitado el 23.04.2018].
} 
PERIN, Andrea. "La redefinición de la culpa (imprudencia) penal médica ante el fenómeno de la medicina defensiva. Bases desde una perspectiva comparada".

A propósito del punto b3 (el facultativo será responsable sólo por impericia grave cuando haya cometido un error ejecutivo en la aplicación de una guía o una buena práctica correctamente elegida): si bien se entienden las razones que subyacen a la reintroducción por vía interpretativa de la distinción entre culpa grave y culpa leve -esto es, evitar que se genere un vacío de protección que exponga la disposición vigente a un posible juicio de incostitucionalidad-, ¿cómo se justifica esta solución frente al dato positivo actual?

Además, y en cuanto al punto $b 2$ (cuando se trate de error ejecutivo, y no existan guidelines o buenas prácticas aplicables al caso clínico - que, por ello, no se han cumplido-, tampoco procederá aplicar la causa de no punibilidad), cabe preguntarse: ¿qué sentido tiene favorecer al facultativo que haya podido contar con guías predeterminadas correctamente elegidas y, sin embargo, haya cometido un error ejecutivo, respecto del profesional que, no pudiendo contar con buenas prácticas predeterminadas (que por ello no han podido ser cumplidas), haya cometido el mismo un error ejecutivo. Nos alejamos, en este sentido, de la ratio de la Ley de 2012.

En cualquier caso, no cabe duda que la "impericia in eligendo" dada por la aplicación de guidelines o protocolos no pertinentes respecto al caso clínico sigue siendo penalmente relevante, conforme se aprecia de la última parte del art. 590 sexies. Bien visto el asunto, sin embargo, aunque el criterio no hubiese sido positivizado y reconocido por la jurisprudencia (punto bl de la solución defendida por el Pleno), esto no podría haber sido de otra manera, pues de lo contrario el médico quedaría facultado para aplicar cualquier lex artis médica válida -aun cuando no tenga ninguna relación con el caso clínico-, para eludir su responsabilidad.

El segundo elemento de novedad de la reforma de 2017 es la regulación de las fuentes (protocolos y guidelines) que pueden heterointegrar el deber de cuidado del facultativo. En efecto, éstas sólo podrán ser elaboradas por los entes, las instituciones públicas o privadas y las sociedades científicas o asociaciones técnico-científicas de las profesiones sanitarias que hayan sido reconocidas conforme a lo establecido por decreto del Ministerio de la Salud (art. $5)^{81}$. Esto explica (pero no justifica, en mi opinión) la no punibilidad del facultativo en caso de inadecuación intrínseca de la lex artis aplicada (allí donde, repito, conforme a la Ley de 2012 quedaba un espacio de punibilidad, en caso de culpa grave). En efecto, conforme a este modelo, el deber de verificar la adecuación de la regla de actuación ya no le corresponde al médico, sino a las instituciones públicas, encargadas de acreditar las leges artis indicadas por la comunidad científica.

Desde la óptica del legislador, semejante solución, al evitar que la valoración recaiga en el profesional, debería significar un avance en términos de seguridad jurídica. Sin embargo, sus

\footnotetext{
81 Sobre la implementación de esta segunda parte de la reforma por medio de los necesarios decretos ministeriales, CUPELLI, Cristiano, 'L'eterointegrazione della legge Gelli-Bianco: aggiornamenti in tema di linee guida 'certificate' e responsabilità penale in ambito sanitario", Diritto Penale Contemporaneo, $\mathrm{n}^{\circ} 10$ (2017), pp. 266-271, en: https:/www.penalecontemporaneo.it/pdf-viewer/?file=\%2Fpdffascicoli\%2FDPC_10_2017.pdf\#page=266 [visitado el 12.01.2018].
} 
Polit. crim. Vol. 13, No 26 (Diciembre 2018) Art. 6, pp. 858-903.

[http://www.politicacriminal.cl/Vol_13/n_26/Vol13N26A6.pdf]

mayores límites se relacionan con la libertad de método y tratamiento ${ }^{82}$, especialmente respecto de aquellos sectores de la medicina que con más dificultad e inconvenientes se dejan formalizar por reglas predeterminadas y por ello "típicas" (por ejemplo, la psiquiatría ${ }^{83}$ ). Esto, como se ha observado, favorece la realización de prácticas de medicina defensiva (de nuevo, el apego acrítico a los protocolos), pero también alimenta el riesgo de inspirar en los intérpretes una sobrevaloración del papel de las guidelines que podría llevar, a su vez, a afirmaciones automáticas de responsabilidad en hipótesis de inobservancia ${ }^{84}$.

\section{La culpa médica como categoría especial}

\subsection{La fragmentación de la categoría}

Uno de los mayores límites de la reforma de 2012 consistía, según argumentaron algunos autores, en la previsión de un régimen sancionador más favorable para los profesionales de la salud, subsistiendo para todos los demás casos el régimen general del art. 43 del Código Penal italiano, el cual no exige (como tampoco lo hace expresamente el art. 491 del Código penal chileno) la culpa grave del profesional. En este sentido, se ha afirmado que "el valor social y las peculiaridades de la actividad médica" no serían suficientes para identificar "un unicum idóneo para legitimar, de por sí, semejante excepción en materia de responsabilidad culposa"85.

La excepción se ha hecho más evidente y las diferencias se han incrementado frente a los demás supuestos de responsabilidad culposa con la introducción de la reforma de 2017 y su respectivo régimen de no punibilidad ${ }^{86}$. Sin embargo, este régimen más favorable sería aplicable sólo en los casos de impericia. Esta interpretación había sido sostenida por algunos autores también respecto de la reforma de $2012^{87}$, siendo confirmada por la jurisprudencia ${ }^{88}$. Actualmente, no cabe duda que la reforma de 2017 se aplica sólo a los supuestos de impericia -ciertos supuestos de impericia, conforme a la interpretación del Pleno de la Casación-.

Respecto a lo anterior, pero más allá de los problemas interpretativos generados por la reforma de 2017, las cuestiones que a mi entender se plantean son dos, a saber: (1) desde un punto de vista axiológico y político-criminal, debemos preguntarnos si es sostenible prever un régimen especial para la culpa médica; (2) desde una perspectiva conceptual, si cabe y es viable a ese fin distinguir la impericia de la imprudencia y la negligencia, como formas de

\footnotetext{
${ }^{82}$ CUPELLI, "Lo statuto", cit. nota no 71, p. 206; IADECOLA, “Qualche riflessione”, cit. nota n 76 , p. 59 s.

${ }^{83}$ Cfr. CUPELLI, Cristiano, "La colpa dello psichiatra", cit. nota n ${ }^{\circ}$ 53, p. 2 s.; MONTANARI VERGALLO, Gianluca; RINALDI, Raffaella; BERSANI, Giuseppe; MARINELLI, Enrico, "Medico-legal notes for a new set of standards in the assessment of penal liability in psychiatry”, Rivista di psichiatria, Vol. 52, n 1 (2017), pp. 16-23, en: http://www.rivistadipsichiatria.it/articoli.php?archivio=yes\&vol_id=2631\&id=27050 [visitado el 14.06.2018].

${ }^{84}$ CUPELLI, "Lo statuto", cit. nota no 71, p. 216.

${ }^{85}$ ROIATI, Alessandro, "Linee guida, buone pratiche e colpa grave: vera riforma o mero placebo?", Diritto penale e processo, $\mathrm{n}^{\circ} 2$ (2013), pp. 216-229, p. 225 (trad. propia).

${ }^{86}$ IADECOLA, "Qualche riflessione", cit. nota $\mathrm{n}^{\mathrm{o}} 76$, p. 59, p. $60 \mathrm{~s}$.

${ }^{87}$ P. ej. RISICATO, L'attività, cit. nota $\mathrm{n}^{\mathrm{o}} 10$, p. 28.

${ }^{88}$ P. ej. la sentencia de la Corte di Cassazione, Sección IV, 24.1.2013, no 11493, Pagano.
} 
PERIN, Andrea. "La redefinición de la culpa (imprudencia) penal médica ante el fenómeno de la medicina defensiva. Bases desde una perspectiva comparada".

culpa merecedoras de diferentes tratos sancionadores.

Nos centraremos de momento en la segunda cuestión.

\subsection{La "imprudencia profesional" en la experiencia española}

En la perspectiva político-criminal que hemos considerado hasta aquí, el carácter profesional de la actividad médica podría justificar una limitación de la intervención penal de cara a los efectos perversos (incluso criminógenos) de ésta. Sin embargo, desde otra perspectiva, la amenaza de graves sanciones lograría inducir al destinatario de la norma penal a subir el nivel de diligencia, impidiendo que siga ejerciendo la profesión o actividad de que se trate cuando haya demostrado no tener aptitudes para ésta. Dicha orientación teleológica general y especial-preventiva explicaría la previsión de la imprudencia profesional en el derecho penal español.

Introducida en el Código penal de 1944, esta figura ha sido objeto de muchas revisiones que han ido modificando su ámbito de aplicación. En un primer momento, éste sólo comprendía las infracciones realizadas en el tráfico viario. Sin embargo, dado que no se entendía "el motivo de por qué otros profesionales, médicos, arquitectos o conductores de trenes, (...) no [habían] de sufrir idénticas agravaciones en sus propias culpas" ${ }^{89}$, asumió sucesivamente un alcance general, hasta que la intervención legislativa del año 1989 limitó su aplicación a los supuestos de imprudencia temeraria ${ }^{90}$.

Hoy el régimen sancionador correspondiente a esta figura es aplicable a los tipos de homicidio, lesiones, aborto y lesiones al feto (arts. 142.3, 146.2, 152.3 y 158.2 del Código penal español). Esto conlleva, además de la pena establecida para el delito-base, la aplicación de la pena accesoria de inhabilitación especial para el ejercicio de la profesión, oficio o cargo, por un periodo de tiempo determinado, según el tipo realizado ${ }^{91}$. Nótese entonces que la imprudencia profesional no se corresponde a un criterio idóneo para definir el límite mínimo de la culpa punible, sino a un concepto que sirve para definir la aplicabilidad de la agravación prevista en caso de culpa grave (o temeraria).

Al principio, esta agravación recibió una aplicación casi automática ${ }^{92}$. Pero la gravedad de las consecuencias sancionadoras prevista por la regulación anterior a $1995^{93}$ indujo

\footnotetext{
89 “(...) siendo así que en no pocas ocasiones los resultados de ellas son harto más catastróficos y espectaculares que las determinadas por vehículos a motor": QUINTANO RIPOLLÉS, Derecho, cit. nota n 2 2, p. 542.

${ }^{90}$ Sobre la reforma de 1989 en esta materia: GARCÍA RIVAS, Nicolás, "La imprudencia «profesional»: una especie a extinguir", en: El nuevo Código Penal: presupuestos y fundamentos. Libro Homenaje al Profesor Doctor Don Ángel Torío López, Granada: Comares, 1999, pp. 369-386, p. 370 s.; ROMEO CASABONA, Carlos María, "Los delitos culposos en la reforma penal", Anuario de derecho penal y ciencias penales, Tomo 43, no 2 (1990), pp. 443-496, p. 450-1, 462-470.

${ }^{91}$ Favorable a la pena accesoria de inhabilitación, por su supuesta mayor eficacia preventiva, CORCOY BIDASOLO, Mirentxu, "Prólogo", en: El delito imprudente. Criterios de imputación del resultado, Montevideo - Buenos Aires: B de F, 2013, XXVI. Sobre la cuestiones que se plantean ante este régimen sancionador, GÓMEZ PAVÓN, Pilar, Tratamientos médicos: su responsabilidad penal y civil, Barcelona: Bosch, 2013, p. $369 \mathrm{~s}$.

92 SILVA SÁNCHEZ, Medicinas, cit. nota n ${ }^{\circ}$ 58, p. 22.

${ }^{93}$ Cuatro años, dos meses y un día como pena base, lo que podía suponer el ingreso en prisión del condenado.
} 
Polit. crim. Vol. 13, No 26 (Diciembre 2018) Art. 6, pp. 858-903.

[http://www.politicacriminal.cl/Vol_13/n_26/Vol13N26A6.pdf]

paulatinamente a la jurisprudencia a distinguir entre la "culpa profesional" (en sentido propio) y la simple "culpa del profesional".

Conforme a la jurisprudencia del Tribunal Supremo español, las graves consecuencias sancionatorias previstas por la primera hipótesis habrían podido justificarse por el carácter profesional de la norma de cuidado inobservada, siendo "imperdonable e indisculpable que una persona que pertenece a una profesión o a la actividad de que se trate y a la que se presumen especiales conocimientos y el dominio de la técnica", realice conductas contrarias a las reglas profesionales correspondientes, y por ello imperitas ${ }^{94}$.

Ahora bien, el dato interesante para nosotros desde una perspectiva comparada es que si bien el concepto de impericia utilizado por el legislador español de la reforma de 1989 -y recogido por la jurisprudencia hasta la actualidad- sirve para definir los casos más graves ("inexcusables") de culpa del profesional, esta asociación, en realidad, ha permitido una marginalización progresiva, por vía interpretativa, de la regulación sancionadora correspondiente (en particular, de la aplicación de la pena accesoria de inhabilitación), toda vez que fuera posible excluir el carácter estrictamente técnico de la pauta incumplida.

Esta operación hermenéutica se ha basado en las sugerencias de la doctrina más sensible al principio de culpabilidad, según la cual el desarrollo de una actividad dada y la calificación subjetiva del autor no podían convertirse en condiciones suficientes para definir como profesional, en sentido propio, una conducta culposa ${ }^{95}$. Sin embargo, y sin perjuicio de que las intenciones del intérprete puedan valorarse positivamente ${ }^{96}$, esta tendencia también ha determinado un estado de objetiva confusión e incerteza jurídica, levantando la cuestión de la labilidad de la frontera entre la impericia y los demás supuestos de culpa (negligencia e imprudencia) $)^{97}$.

En efecto, si bien según algunas sentencias el carácter profesional de la culpa resultaría del carácter técnico de la lex artis inobservada-siempre que la inobservancia del cuidado debido se deba a la falta de los conocimientos técnicos necesarios y exigibles para el ejercicio de la

\footnotetext{
Aunque la sanción actual se puede considerar incluso más aflictiva respecto del aumento previsto por la regulación anterior.

${ }^{94}$ Así, p. ej., la sentencia del Tribunal Supremo de 22 de abril de 1988 (cit. por SILVA SÁNCHEZ, Medicinas, cit. nota $\mathrm{n}^{\circ} 58$, p. 22); de la misma forma, la sentencia del Tribunal Supremo de 18 de noviembre de 1991, en el caso citado arriba, nota ${ }^{\circ} 64$.

95 A este respecto, cfr. COBOS GÓMEZ DE LINARES, Miguel Ángel, "El problema de las lagunas «conscientes» y la jurisprudencia «creativa» a través de un ejemplo: la distinción entre culpa profesional y culpa del profesional", Poder Judicial, no 18 (1990), pp. 113-132, p. 114 s.; FEIJÓO SÁNCHEZ, Bernardo José, "La imprudencia en el Código penal de 1995 (cuestiones de lege data y de lege ferenda)", Cuadernos de Política Criminal (1997), pp. 303-365, p. 335 s.

${ }^{96} \mathrm{Al}$ menos en opinión de GARCÍA RIVAS, "La imprudencia", cit. nota no 90, p. 370 s.

${ }^{97}$ Como demuestran los estudios jurisprudenciales de GARCÍA RIVAS, "La imprudencia" cit., nota no 90, p. 373 s., y URRUELA MORA, Asier; ROMEO MALANDA, Sergio, Tendencias actuales de la jurisprudencia española, en: ROMEO CASABONA, El médico (t. II), cit. nota nº 11, pp. 579-605, p. 586, 589 s.
} 
PERIN, Andrea. "La redefinición de la culpa (imprudencia) penal médica ante el fenómeno de la medicina defensiva. Bases desde una perspectiva comparada".

profesión ${ }^{98}$ - existen fallos que, además de los supuestos de ignorancia inexcusable, incluyen también aquellos en los que, pese a que el profesional posea los conocimientos exigidos, haya habido una ejecución defectuosa del acto requerido profesionalmente ${ }^{99}$.

\subsection{Crítica al concepto de "impericia" como medio de discriminación a efectos de la penalidad}

La comparación entre la experiencia italiana y la española es llamativa. En Italia, el concepto de impericia sirve para definir el ámbito de aplicación de un régimen más favorable, que prevé, según el caso, la exclusión de la culpa leve o de la relevancia penal de la culpa tout court. Esta opción político-criminal se justificaría por las mayores dificultades relacionadas con el ejercicio de la profesión y por la finalidad de hacer frente al fenómeno de la medicina defensiva. En España, en cambio, la misma categoría sirve para determinar los casos de culpa profesional (de por sí grave, o temeraria), caracterizados, además, por un "plus de antijuridicidad", siendo "injustificable e imperdonable" cualquier error relacionado con el cumplimiento de las leges artis, sobre la base de exigencias general y especial-preventivas.

Las razones y las finalidades que inducen en uno y en otro contexto a acudir al concepto de impericia son, entonces, distintas. Con todo, en ambas experiencias dicha noción ha generado un estado de incertidumbre.

Tratándose del caso español, en ocasiones ha permitido marginalizar la figura de la culpa profesional según si la orientación jurisprudencial adoptada por los tribunales permite incluir sólo los supuestos de ignorancia, o también aquellos de errónea aplicación de la lex artis ${ }^{100}$. En lo que atañe a Italia, dicha incertidumbre se manifiesta sobre todo en el riesgo de que, a fines acusatorios, se puedan convertir supuestos de impericia (sujeta, en ciertos casos, a un régimen más favorable) en imputaciones por negligencia e imprudencia (penalmente relevantes, en cualquier caso) ${ }^{101}$.

No obstante, en ambas experiencias la jurisprudencia tiende a considerar menos reprochable

98 Sobre la jurisprudencia del Tribunal Supremo español en este sentido: FEIJÓO SÁNCHEZ, "La imprudencia", cit. nota $n^{\circ}$ 95, p. 336-7; GRATACÓS GÓMEZ, Nuria, "La imprudencia en el nuevo código penal. Especial referencia de la imprudencia profesional y la inhabilitación especial para el ejercicio de una profesión, oficio o cargo", Derecho y Salud, Vol. 5, no 1 (1997), pp. 62-75; GUTIÉRREZ ARANGUREN, José Luis, "La imprudencia profesional", en: JUANE SÁNCHEZ, Miguel, et al (Coord.), Lecciones de derecho sanitario (1999), pp. 391-408, p. 399 s.

${ }^{99}$ Así, en la jurisprudencia citada por URRUELA MORA; ROMEO MALANDA, Tendencias, cit. nota $\mathrm{n}^{\circ}$ 97, p. 586, 589-591. Véanse en particular los fallos citados en la p. 590, donde se observa que el mismo tipo de negligencia cometida por médicos anestesistas puede dar lugar, según el caso, a diferentes calificaciones jurídicas. Asimismo, en el caso mencionado en la nota $n^{\circ} 64$ de la presente contribución, mientras que la Audiencia Provincial condenó ambos imputados por imprudencia temeraria y profesional (SAP Barcelona, 20.11.1989), el Tribunal Supremo confirmó dicha evaluación en cuanto al grado de la culpa del director, pero excluyendo su carácter profesional. Así la sentencia del Tribunal Supremo de 18 de noviembre de 1991: "La culpa profesional es equivalente a impericia porque descansa en el defectuoso cumplimiento de las reglas de la lex artis, si bien no se desconoce la a veces difícil delimitación de los dos contenidos imprudentes".

100 También por ello, un sector de la doctrina aboga por su supresión, según señalan URRUELA MORA; ROMEO MALANDA, Tendencias, cit. nota n ${ }^{\circ}$ 97, p. 586.

${ }^{101}$ CUPELLI, "Lo statuto", cit. nota ${ }^{\circ}$ 71, p. 208 s., quien destaca como en la jurisprudencia de la Corte di Cassazione sobre la reforma de 2012, el supuesto de retraso en la investigación diagnóstica figura calificado, según el caso, como hipótesis de negligencia o de impericia. 
Polit. crim. Vol. 13, No 26 (Diciembre 2018) Art. 6, pp. 858-903.

[http://www.politicacriminal.cl/Vol_13/n_26/Vol13N26A6.pdf]

el error ejecutivo respecto a la ignorancia culpable. En efecto, mientras el error ejecutivo se suele excluir de la noción de "imprudencia profesional" (según la mencionada orientación de la jurisprudencia española), y se considera penalmente irrelevante, cuando es cometido en el cumplimiento de buenas prácticas (según el Pleno de la Casación italiana - punto b3), los supuestos de ignorancia culpable representan las formas típicas de "imprudencia profesional", en el primer contexto, quedando excluidos del régimen más favorable, en el segundo.

La relatividad de la distinción conceptual entre negligencia, imprudencia e impericia ya había sido señalada hace tiempo por la doctrina italiana. "Tanto si la impericia surge de la ignorancia de las nociones necesarias para la profesión o arte, o de la inhabilidad para aplicar dichas nociones (independientemente si el sujeto es consciente de estas faltas); como si el sujeto, aun poseyendo las informaciones y las capacidades requeridas, en concreto no las aplica, lo que deberá valorarse en el juicio será, en todo caso, la objetiva discrepancia entre la conducta realizada y aquella que las normas de la profesión o del arte hubieran prescrito"102. Al fin y al cabo, "la impericia no es otra cosa que una imprudencia o una negligencia calificadas, según la regla técnica inobservada prescriba abstenerse de cierta conducta o algunas modalidades de ésta, o bien la realización de un comportamiento positivo" $"$.

Según ha sostenido Marcello Gallo, un elemento variable de impericia subsistiría siempre que el carácter culposo encuentre su origen en una diferencia (el dualismo de donde surge la culpa) entre el nivel de conocimiento del parámetro - la expectativa normativa- y aquel del autor del hecho (en los supuestos de ignorancia); pero también en aquellos casos en los cuales éste no sea capaz de aplicar los conocimientos necesarios, aún poseídos (en los supuestos de error técnico o ejecutivo); y, finalmente, cuando el mismo no sepa reconocer la ocasión para utilizarlos (error de hecho sui generis).

Como se ha defendido también en la doctrina española, no se puede pensar que los deberes inherentes al ejercicio de una profesión, por técnicos (específicos, sectoriales, etc.) que éstos sean, no hagan propias, en el fondo, normas de prudencia o diligencia ${ }^{104}$. Por consiguiente, si la impericia se convierte en una categoría meramente indicativa de supuestos de imprudencia o negligencia, aunque calificadas por referirse al ejercicio de una determinada profesión o arte -y por ello inidónea para justificar la aplicación de un régimen sancionador especial-, la verdadera cuestión que deberíamos afrontar vuelve a ser la señalada al cerrar el apartado 6.1, esto es, si y, en su caso, cuándo, desde una perspectiva político-criminal, se justifica una diferenciación o fragmentación de la categoría de la culpa frente a los efectos que su aplicación pueda tener en cada ámbito profesional y de la vida de relación.

\footnotetext{
102 GALLO, “Colpa”, cit. nota n 45, p. 641.

${ }^{103}$ Del mismo parecer, MARINUCCI, La colpa, cit. nota $\mathrm{n}^{\circ} 2$, p. 216.

104 SILVA SÁNCHEZ, Medicinas, cit. nota $\mathrm{n}^{\circ}$ 58, p. 24. De manera semejante, en Italia, DI GIOVINE, "In difesa", cit. nota $n^{\circ} 63$, p. 6 s., quien, comentado y defendiendo la reforma de 2012, observa que "en la realidad de los casos complejos, la frontera entre el [des]conocimiento, el uso [in]adecuado del mismo, la imprudencia o la negligencia en la elección de aquello adecuado, parece demasiado incierta, y por ello demasiado peligrosa una distinción que quiera ser dirimente a los efectos de la penalidad" (trad. esp. nuestra).
} 
PERIN, Andrea. "La redefinición de la culpa (imprudencia) penal médica ante el fenómeno de la medicina defensiva. Bases desde una perspectiva comparada".

\section{Síntesis y bases para una propuesta dogmática. A propósito del art. 491 del Código Penal chileno}

Las reflexiones desarrolladas en las secciones anteriores, a propósito de la experiencia italiana y española, también pueden ser útiles para el contexto chileno, donde se han planteado cuestiones semejantes (respecto a la graduación de la responsabilidad por culpa y la valoración del poder normativo -y sus límites-de las guidelines) de cara a la manifestación del fenómeno en cuestión (judicialización de la actividad médica, objetivización de los criterios de imputación, medicina defensiva $)^{105}$.

La heterointegración normativa del cuidado debido por medio de fuentes técnicas supone cuestiones de carácter eminentemente metodológico, relacionadas con la naturaleza de dichas fuentes, sus contenidos técnicos, y su relevancia para la definición del riesgo permitido y el umbral de la punibilidad. En cuanto a la valoración del grado de la culpa, en cambio, hay que tener en cuenta el dato positivo.

Según la doctrina ${ }^{106}$ y la jurisprudencia ${ }^{107}$ chilenas al parecer prevalentes, el art. 491 del Código penal ${ }^{108}$ no exige la culpa grave. Esto sería así no sólo porque el art. 490, al requerir expresamente la imprudencia temeraria, dejaría inferir a contrario que la disposición

\footnotetext{
105 Como apunta VARGAS PINTO, “Algunos antecedentes”, cit. nota $n^{\circ}$ 8, p. 352: "En pocos años se pasó del rechazo a una especie de responsabilidad por todo evento". En el mismo sentido crítico, observando así mismo una excesiva normativización de la imprudencia (o culpa) en materia de responsabilidad médica, MATUS ACUÑA, Jean Pierre, "Mala praxis como sinónimo de negligencia y la «normativización» de la responsabilidad penal médica en la reciente jurisprudencia de la Corte Suprema de Chile ¿Un camino hacia la responsabilidad penal objetiva?” (2009). En: http://www.microjuris.cl/home.jsp.

106 Véanse a este propósito y para más referencias: VARGAS PINTO, "La imprudencia”, cit. nota n 27, p. 114; MARTÍNEZ, "La graduación”, cit. nota n 8, p. 215 s.; CONTRERAS, Lautaro, "Reglas extrajurídicas y creaciones de riesgos toleradas o desaprobadas en los delitos culposos de homicidio y lesiones", Política Criminal, Vol. 13, $\mathrm{n}^{\mathrm{o}} 25$ (2018), pp. 387-444, p. 398 y nota 41, en: http://www.politicacriminal.cl/Vol_13/n_25/Vol13N25A11.pdf [visitado el 14.06.2018]. Referencias en sentido contrario en REYES ROMERO, Ítalo, "Una aproximación a la imputación a título de imprudencia en el Código penal chileno", Revista de Derecho de la Pontificia Universidad Católica de Valparaíso, Vol. XLVII (2016), pp. 245-278, p. 272 s., 275.

107 Ver p. ej. la Sentencia de la Corte de Apelaciones de Santiago, de 5 de junio de 2001, Rol: 35518-1998, cit. por VARGAS PINTO, "Algunos antecedentes", cit. nota $\mathrm{n}^{\circ}$ 8, p. 362, nota 44; la jurisprudencia citada y comentada por MATUS ACUÑA, "Mala praxis", cit. nota n 105; la Resolución No 31390 de la Corte de Apelaciones de San Miguel, de 16 de agosto de 2011, Causa No 240/2011, en: http://vlex.com/vid/-313000630; la Resolución No 233422 de la Corte de Apelaciones de Santiago, de 2 de agosto de 2012, Causa No 2740/2011, en: http://vlex.com/vid/landa-tobar-octavio-c-573042290. Véase, sin embargo y en sentido contrario (asunción implícita -y expresa, en algunos casos- del criterio de la culpa grave), las sentencias citadas por MARTÍNEZ, "La graduación", cit. nota $\mathrm{n}^{\circ}$ 8, p. 245 s. Más referencias acerca de los criterios de imputación adoptados por la jurisprudencia nacional en VARGAS PINTO, Tatiana, Responsabilidad penal por imprudencia médica. Un examen práctico de los principales problemas para la determinación del cuidado debido, Santiago: Der Ediciones, 2017, p. 11 s., 97 s.

108 “El médico, cirujano, farmacéutico, flebotomiano o matrona que causare mal a las personas por negligencia culpable en el desempeño de su profesión, incurrirá respectivamente en las penas (...)" establecidas por al art. 490 del mismo Código. En este ordenamiento, además, al facultativo se le puede castigar a título de falta por mera negligencia sin resultado lesivo, sobre la base del art. 494, inc. 10.
} 
Polit. crim. Vol. 13, No 26 (Diciembre 2018) Art. 6, pp. 858-903.

[http://www.politicacriminal.cl/Vol_13/n_26/Vol13N26A6.pdf]

sucesiva exigiría, en cambio, algo menos ${ }^{109}$; sino también por razones relacionadas con el tipo de actividad (altamente riesgosa) y los bienes jurídicos involucrados (fundamentales). Esta interpretación reflejaría entonces la misma ratio preventiva que subyace a la previsión de la imprudencia profesional en el sistema español ${ }^{110}$, y también a ciertas orientaciones jurisprudenciales algo paternalistas en materia prevención de riesgos laborales en las mismas experiencias consideradas ${ }^{111}$.

Sin embargo, algunos autores han defendido que dicha disposición debería, en cambio, interpretarse en el sentido de exigir la culpa grave ${ }^{112}$. El principal argumento de esta inteligencia descansa no sólo en el hecho que los profesionales médicos "dedican la mayor parte de su tiempo a esas actividades y colocarlos en una situación de responsabilidad por la mera imprudencia" sería "a lo menos, poco realista" "113, sino también, precisamente, en la necesidad de hacer frente a la medicina defensiva ${ }^{114}$. Es decir, no ya por motivos puramente hermenéuticos, sino por razones de carácter eminentemente político-criminal.

El debate está abierto, y con el fin de aportarle otros elementos, trataré a continuación de resumir algunas sugerencias y advertencias deducibles desde la perspectiva comparada considerada en este estudio.

En cuanto a las reformas adoptadas por el legislador italiano, considero que la Ley de 2012, pese a sus límites, proporciona una buena orientación hacia un camino equilibrado. Por lo pronto, es lo que hace al mantener la responsabilidad del facultativo allí donde se le puede

109 GARRIDO MONTT, Mario (1997), Derecho Penal: Parte General, t. II, Santiago: Editorial Jurídica de Chile, p. 173. Esta interpretación nos llevaría a una situación parecida a la española tras la reforma implementada por la Ley Orgánica 1/2015, que introduce la distinción entre la imprudencia grave y la imprudencia menos grave, siendo esta última a su vez distinta de la imprudencia leve (despenalizada en ese ordenamiento, debido a la eliminación de las faltas). Según destaca a este propósito ROMEO CASABONA, Carlos María, "El tipo del delito de acción imprudente", en: ROMEO CASABONA, Carlos M.; SOLA RECHE, Esteban; BOLDOVA PASAMAR, Miguel Á. (Coords.), Derecho penal. Parte general - Introducción a la teoría jurídica del delito (2a ed.), Granada: Comares, 2016, pp. 133-148, p. 144, "el legislador [español] ha querido otorgar un contenido propio a la imprudencia menos grave, que en todo caso deberá ser de superior gravedad que la desaparecida imprudencia leve", suponiendo esto, sin embargo, dejar "un margen muy amplio de discrecionalidad a los tribunales respecto a lo que abarque la imprudencia punible y no punible". En efecto, si ya es complicado distinguir teórica y prácticamente la culpa grave de la culpa leve, más difícil aún resulta comprender la previsión de una especie intermedia.

110 Véase CURY URZÚA, Enrique, “Contribución al estudio de la responsabilidad médica por hechos culposos”, Revista de Ciencias Penales, t. XXXVII (1981), pp. 97-105, p. 105.

${ }^{111}$ Véase PERIN, Andrea, "La contribución de la víctima y la imputación objetiva del resultado en la teoría del delito imprudente. Un estudio comparado en materia de prevención de riesgos laborales", Revista Electrónica de Ciencia Penal y Criminología, no 18 (2016), pp. 1-27, p. 5 s., en: http://criminet.ugr.es/recpc/18/recpc1803.pdf [visitado el 12.01.2018].

112 P. ej. BUSTOS RAMÍREZ, Juan, El delito culposo, Santiago: Ed. Jurídica de Chile, 1995, p. 56. Véanse también las dos notas sucesivas.

113 “(...) ya que, como se sabe, el más competente de los profesionales comete alguna vez alguna falta”: POLITOFF L., Sergio; MATUS A., Jean Pierre; RAMÍREZ G., María Cecilia, Lecciones de Derecho Penal Chileno. Parte General, Santiago: Editorial Jurídica de Chile, 2003, p. 292. Los autores, sin embargo, en la nota 351 reconocen que político criminalmente es más oportuna una solución parecida a la adoptada por el Código Penal español (pena accesoria de inhabilitación, en caso de imprudencia profesional temeraria).

114 MARTÍNEZ, "La graduación”, cit. nota no 8, p. 217 s., 236 s. 
PERIN, Andrea. "La redefinición de la culpa (imprudencia) penal médica ante el fenómeno de la medicina defensiva. Bases desde una perspectiva comparada".

exigir la adopción de una regla de cuidado distinta a la aplicada habitualmente -por ser ésta claramente inadecuada (por ejemplo, técnicamente obsoleta)-, pero sólo en caso de culpa grave. En efecto, de este modo, si bien por un lado se le atribuye al profesional la responsabilidad de evaluar críticamente las opciones diagnósticas y terapéuticas disponibles $^{115}$, por otro lado, también se reconoce y valora la mayor dificultad dada por la necesidad de alejarse de una pauta de conducta en la que, al menos en principio (salvo la necesidad patente de actuar de otra manera ${ }^{116}$ ), el facultativo debería poder confiar.

No obstante, la misma dificultad también subsiste -y así mismo debería ser valorada por el legislador y/o el intérprete, en mi opinión- en los supuestos en que el facultativo cuenta con ninguna pauta de conducta predeterminada, debiendo acudir a lo que haría un profesional prudente (sensato, etc.) en una situación semejante.

En ambas circunstancias, pese a los problemas definitorios que esta noción lleva consigo, la limitación de la intervención penal a los casos de culpa grave ${ }^{117}$ podría concurrir a atenuar la medicina defensiva y permitir a los tribunales de justicia penal ocuparse de forma más detenida de los casos realmente preocupantes e injustificables de mala praxis médica, dejando los demás bajo la competencia del derecho civil. El desafío consistiría, pues, en trazar claramente la frontera entre la culpa penal y la culpa civil.

En esta dirección, el debate acerca de la oportunidad de reducir la culpa penal a la sola infracción de pautas de cuidado "típicas" (i.e., predeterminadas), y la cuestión de la heterointegración normativa del deber de cuidado por medio de fuentes técnicas, nos ofrecen otras buenas bases de orientación. Concretamente, nos permiten tomar como punto de partida el hecho de que existen circunstancias típicas donde el facultativo puede contar con instrucciones pre-determinadas ("típicas", en el sentido ya mencionado, aunque no necesariamente establecidas por protocolos u otras fuentes escritas), y casos clínicos o riesgos atípicos, frente a los cuales el mismo facultativo no cuenta con reglas predefinidas (ni tampoco el juez, a la hora de evaluar su eventual responsabilidad), debiendo por ello adoptar estrategias diagnósticas o terapéuticas "atípicas" (dejando de aplicar, en su caso, las pautas generalmente adoptadas en casos similares) $)^{118}$.

El criterio de la gravedad vendría en causa precisamente en estas segundas circunstancias, lo que nos podría llevar a definir y adoptar una concepción comparativa del mismo. Es decir, en el sentido de que la infracción de una expectativa de cuidado "atípica" (i.e., no pre-

\footnotetext{
115 Sobre esto, DI LANDRO, Dalle linee, cit. nota $\mathrm{n}^{\circ} 75$, p. $155 \mathrm{~s}$.

${ }^{116}$ Como en el caso mencionado en la nota ${ }^{\circ} 64$.

117 En esta misma dirección, véanse: la propuesta definitoria de FORTI; CATINO; D’ALESSANDRO; MAZZUCATO; VARRASO, Il problema, cit. nota $\mathrm{n}^{\mathbf{0}}$ 39, p. 199, quienes, adoptando las nociones de Leichtfertigkeit y grobe Fahrlässigkeit, definen "grave" la culpa "cuando la acción o la omisión de quien ejerce la profesión sanitaria, grandemente inobservante de las leges artis, ha generado un riesgo irrazonable para la salud del paciente, que se ha realizado en el resultado" (original en italiano: "quando l'azione o l'omissione dell'esercente una professione sanitaria, grandemente inosservante di regole dell'arte, ha creato un rischio irragionevole per la salute del paziente, concretizzatosi nell'evento"); o bien, en la discusión chilena, los criterios indicados por MARTÍNEZ, "La graduación", cit. nota nº 8, p. 236 s., 239 s., con mayor referencia a la experiencia española.

${ }^{118}$ PERIN, "La condotta", cit. nota no 7, p. 223 s., 253 s., y las referencias allí citadas.
} 
determinada por lo usual y las leges artis) podría ser considerada tan grave como para merecer la misma relevancia (penal) atribuida a la inobservancia de las normas modales predefinidas ("típicas"), bajo la condición que el cumplimiento de esa expectativa de cuidado ajustada a la Maßfigur (la persona sensata, razonable, eiusdem condicionis et professionis) pueda valorarse objetivamente exigible de la misma manera ${ }^{119}$.

La reforma de 2017 ha dado, en cambio, algún paso hacia atrás. El hecho que se excluya la responsabilidad del médico, bajo la condición que éste haya cumplido con los protocolos o indicaciones similares pertinentes al caso clínico, va en la dirección contraria de favorecer una actitud que indudablemente estimula la medicina defensiva, además de suponer posibles perjuicios para la libertad de método y tratamiento ${ }^{120}$.

Finalmente, sobre la base de las experiencias consideradas y de las críticas planteadas desde el punto de vista conceptual, cabe destacar que la noción de impericia se ha revelado inadecuada para definir el ámbito de aplicación de un régimen sancionador diferenciado. Y la cuestión de si $-\mathrm{y}$, en su caso, en qué medida- es oportuno prever una diferenciación respecto de ciertos sectores profesionales o actividades, asume un carácter eminentemente político-criminal, pues implica llevar a cabo una valoración acerca de los efectos positivos o negativos que la intervención penal pueda tener en el sector de que se trate.

En el caso de la actividad médica, la experiencia está demostrando que la amenaza penal, más que favorecer la protección de la salud, constituye a menudo un incentivo para realizar conductas que responden más al temor a la sanción que al objetivo de perseguir el bien del paciente.

\section{Cuestiones abiertas y perspectivas}

El panorama de las opciones político-criminales planteadas para hacer frente al fenómeno de la medicina defensiva, y reducir el recurso a la vía penal, no se acaba en la consideración de la limitación del alcance de la culpa penal médica. En los últimos años, tanto en Chile como en el derecho comparado, se ha retomado el debate acerca de la figura de "tratamientos médicos arbitrarios"121 y se han planteado medidas de justicia reparativa, favoreciendo los

\footnotetext{
${ }^{119}$ En este sentido (con algún cambio en la formulación), PERIN, "La condotta”, cit. nota n 7 , p. 237 s., 248 9, 251, 253. Este criterio de gravedad reflejaría al fin y al cabo una ratio parecida a la subyacente a la previsión del art. 492 del Código Penal chileno, que impone las mismas penas del art. 490 (imprudencia temeraria), “(...) al que, con infracción de los reglamentos y por mera imprudencia o negligencia (...)” ejecutare los hechos allí indicados. Como observa NÁQUIRA RIVEROS, Jaime, Derecho Penal Chileno. Parte General, t. I, Santiago: Legal Publishing Chile, 2015, p. 253, "la idea para una mayor agravación (...) vendría dada por el hecho que la ley ha facilitado al autor su conocimiento o investigación, al establecer de manera expresa cómo tiene que comportarse en un caso concreto". Lo mismo valdría para las pautas predeterminadas por fuentes sociales, no necesariamente escritas, pero en todo caso "típicas" (en el sentido ya aclarado).

${ }^{120}$ Que permite a su vez la evolución de las prácticas clínicas: ROMEO CASABONA, El médico (t. II), cit. nota $\mathrm{n}^{\circ} 11$, p. $269 \mathrm{~s}$.

121 Véase sobre este concepto, su regulación jurídica y la discusión que se ha desarrollado a su alrededor en otras experiencias continentales: ROMEO CASABONA, Carlos María, El médico y el Derecho Penal, t. I, La actividad curativa. Licitud y responsabilidad penal, Santa Fe: Rubinzal-Culzoni, 2011, p. 323 s.; MANNA, Adelmo, Profili penalistici del trattamento medico-chirurgico, Milano: Giuffrè, 1984, p. 149 s. Para algunas
} 
PERIN, Andrea. "La redefinición de la culpa (imprudencia) penal médica ante el fenómeno de la medicina defensiva. Bases desde una perspectiva comparada".

procesos de mediación y los acuerdos reparatorios ${ }^{122}$.

Desde luego, estas estrategias merecen ser estudiadas aparte, aunque la definición de la cuestión tratada aquí no les es indiferente. En efecto -siempre tratándose del caso chileno-, si bien se ha destacado que el Código Procesal Penal actual restringiría "en forma significativa la posibilidad de intentar la acción civil en el proceso penal" - con lo que los problemas de responsabilidad médica deberían ser conocidos por los jueces civiles más que por los jueces penales ${ }^{123}$-, también se puede sostener que la deseable "tendencia a excluir la responsabilidad penal de los médicos, salvo situaciones de carácter grave o de actos dolosos" $" 124$, necesitaría el respaldo de previsiones (léase: limitaciones) coherentes en el plano sustantivo $^{125}$.

Por eso, teniendo en cuenta las estrategias consideradas en este trabajo y, en particular, la oportunidad de redefinir la culpa como criterios de imputación ex ante, cabe reconocer que la aceptación de las premisas de nuestro discurso supone, en todo caso, tener que afrontar al menos las siguientes cuestiones.

En primer lugar, el problema de si realmente las características intrínsecas del sector médico justifican un cambio de rumbo (como ha intentado hacer el legislador italiano). Como ya anticipamos, al respecto se plantea la cuestión de si esto supondría o no una vulneración del principio de igualdad frente a otras categorías profesionales o actividades, lo que llevaría, en

propuestas de configuración e introducción de un tipo delictivo correspondiente en la doctrina más reciente: VALLINI, "Paternalismo", cit. nota no 16, p. 10; RODRÍGUEZ VÁZQUEZ, Virgilio, "El delito de tratamiento médico arbitrario", Revista Electrónica de Ciencia Penal y Criminología, no 19-3 (2017), pp. 1-59, p. 50 s. Sin embargo, frente a estas propuestas, se argumenta (con razón, en mi opinión) que la introducción de dicha figura podría favorecer aún más ciertas prácticas de medicina defensiva: así, p. ej., EUSEBI, "Medicina", cit. nota no 32, pár. 3; cfr. al respecto las reflexiones conclusivas de HERNÁNDEZ BASUALTO, "Consentimiento", cit. nota ${ }^{\circ} 27$, p. 183-5.

${ }^{122}$ En argumento, CARNEVALI RODRÍGUEZ, Raúl, "La justicia restaurativa como mecanismo de solución de conflictos. Su examen desde el derecho penal", Justicia Juris, Vol. 13, no. 1 (2017), pp. 122-132.

${ }^{123}$ PIZARRO W., Carlos, "Responsabilidad profesional médica: Diagnóstico y perspectivas", Revista Médica de Chile, Vol. 136, no 4 (2008), pp. 539-543, p. 540 (cursiva añadida). En Chile, para los delitos culposos se prevé la posibilidad de acudir a acuerdos reparatorios con el efecto de extinguir la acción penal pública (art. 241 del Código Procesal Penal), además de la posibilidad del imputado de acceder a la suspensión condicional del procedimiento, indemnizando a la víctima (art. 238, letra $e$ ). Sin embargo, las demoras de los juicios civiles, junto con la posibilidad de acudir al juez penal con el objetivo principal o exclusivo de presionar al supuesto culpable y conseguir de esta forma una indemnización, hacen que estas estrategias no hayan conseguido los resultados esperados. En cuanto a la Jurisdicción civil, la Ley 19.966 del año 2004 establece que quien crea haber sufrido un caso de mala praxis médica no podrá acudir a tribunales de justicia sin antes haber "sometido su reclamo a un procedimiento de mediación ante el Consejo de Defensa del Estado", con el objetivo de "propender a que, mediante la comunicación directa entre las partes y con intervención de un mediador, ellas lleguen a una solución extrajudicial de la controversia" (art. 43: mecanismo de mediación obligatoria). Más referencias en MARTÍNEZ, "La graduación", cit. nota no 8, p. $224 \mathrm{~s}$.

${ }^{124}$ PIZARRO W., "Responsabilidad", cit. nota no 123, p. 543 (cursiva añadida).

${ }^{125}$ En este mismo sentido, el citado proyecto de lege ferenda elaborado por el "Centro Studi Federico Stella" (FORTI; CATINO; D'ALESSANDRO; MAZZUCATO; VARRASO, Il problema, cit. nota $\mathrm{n}^{\circ}$ 39) se basa en dos opciones principales complementarias: (1) la limitación de la culpa médica conforme al criterio de la gravedad; (2) la realización de programas de justicia reparativa. Sobre la oportunidad de conjugar ambos aspectos, véase de nuevo D’ALESSANDRO, Francesco, "Contributi", cit. nota $\mathrm{n}^{\circ} 30$, § 4; RISICATO, L'attività, cit. nota $\mathrm{n}^{\circ} 10, \mathrm{p} .78 \mathrm{~s}$. 
caso de ser así, a una inoportuna fragmentación de la categoría dogmática en cuestión.

Desde luego, el problema no es nuevo. Tal como anotáramos precedentemente, ello se planteó a propósito de la "imprudencia profesional" en el sistema español (figura que en un principio sólo se aplicaba al tráfico viario, para luego asumir un alcance general), así como se plantea ahora frente a las reformas italianas. En efecto, si bien para un sector de la doctrina sería oportuno extender el mismo régimen o trato sancionador a todas las actividades caracterizadas por la asunción de riesgos permitidos debido a su reconocida utilidad social ${ }^{126}$, otros autores destacan la necesidad de considerar las peculiaridades del ámbito médico desde la perspectiva político-criminal, sin que la unidad de la "culpa" como categoría se pueda considerar como un valor en sí mismo (o en todo caso prevalente) ${ }^{127}$.

En segundo lugar, y asumiendo que se estime necesario redefinir la culpa médica (aunque sea simplemente para corregir ciertas tendencias objetivizantes de la jurisprudencia ${ }^{128}$ ), cabe preguntarse si esto debe plantearse de iure condito, esto es, a través de "nuevas indicaciones doctrinales que hagan más comprensibles y previsibles los criterios de imputación" 129 (como el criterio de gravedad sugerido en este trabajo), o bien de lege ferenda, es decir, buscando una redefinición de consenso de la culpa médica como categoría positiva ${ }^{130}$.

Como demuestra claramente la experiencia italiana, no se deben olvidar los límites y los peligros de cualquier intento definitorio, incluso si éstos están inspirados por los más nobles intentos garantistas ${ }^{131}$. Asimismo, no se debe caer en el error que supondría creer que una definición en abstracto del criterio de imputación (incluso dogmática o legislativamente consensuada) permitirá proporcionar a los jueces baremos o indicaciones capaces, por sí solas, de indicar la solución correcta del caso por decidir ${ }^{132}$.

\footnotetext{
${ }^{126}$ P. ej., ROIATI, “Linee guida”, cit. nota $\mathrm{n}^{\mathrm{o}} 85$, p. 225-6.

${ }^{127}$ Véase CAPUTO, “Agente modello, cit. nota no 38, p. 105 s., 126 s., y RISICATO, L'attività, cit. nota n ${ }^{\circ} 10$, p. 15 s., 22-3.

${ }^{128}$ Referencias en las notas $\mathrm{n}^{\mathbf{0}} 105$ y 107.

${ }^{129}$ Así, el EVALUADOR 1 encargado por Conicyt -a quien agradezco la observación- respecto del proyecto de investigación en cuyo marco se publica este artículo $(*)$.

${ }^{130}$ Como en la propuesta defendida en Italia por FORTI; CATINO; D’ALESSANDRO; MAZZUCATO; VARRASO, Il problema, cit. nota $\mathrm{n}^{\circ}$ 39, p. 199 (ver notas $\mathrm{n}^{\mathrm{o}} 117$ y 125). Sobre esta cuestión, ver en otro contexto la discusión crítica de FRAKES, Michael D., "The Surprising Relevance”, cit. nota n 24, p. 350 s., 374 s., 385.

131 Véase MELCHIONDA, Alessandro, "Definizioni normative e riforma del codice penale (spunti per una rinnovata riflessione sul tema)", en: CADOPPI, Alberto (Ed.), Omnis definitio in iure periculosa? Il problema delle definizioni legali nel diritto penale, Padova: Cedam, 1996, pp. 391-429, p. 408 s., 413-4, quien argumenta claramente la dificultad de conjugar, por un lado, la exigencia (típicamente expresada por la ciencia penal alemana) de evitar que sea el legislador el llamado a elegir de forma unilateral allí donde el debate científico todavía no ha alcanzado un nivel suficiente de homogeneidad dogmática y, por otro lado, la aspiración a una mayor taxatividad del sistema de la Parte General.

132 Como nos recuerdan POLITOFF L.; MATUS A.; RAMÍREZ G., Lecciones, cit. nota n ${ }^{\circ} 113$, p. 27, a propósito de la codificación liberal, “con sutil ironía, Silvela se refería en 1879 a esta pretensión de suplantar por la vía legal la actividad judicial, afirmando que «por ese camino se ha llegado a conseguir lo que según algunos debe suponerse era el desiderátum de los legisladores del Código, a saber, que pudieran dictarse sentencias medianamente justas con jueces medianamente ignorantes»»".
} 
PERIN, Andrea. "La redefinición de la culpa (imprudencia) penal médica ante el fenómeno de la medicina defensiva. Bases desde una perspectiva comparada".

\section{BIBLIOGRAFÍA}

BARON, Marcia, "The Standard of the Reasonable Person in the Criminal Law”, en: DUFF, R.A.; FARMER, Lindsay; MARSHALL, S.E., RENZO, Massimo; TADROS, Victor (Eds.), The Structures of the Criminal Law, Oxford: Oxford University Press, 2012, pp. 1-30.

BARREDA, Iñigo, "La medicina defensiva: Tendencias y experiencias en el ámbito internacional", Revista Conamed, Vol. 4, nº 13 (1999), pp. 18-21.

BARTOLI, Roberto, "I costi 'economico-penalistici' della medicina difensiva", Rivista italiana di medicina legale, $\mathrm{n}^{\circ}$ 4-5 (2011), pp. 1107-1123.

BECK, Ulrich, Conditio humana. Il rischio nell'età globale, Roma - Bari: Laterza, 2011.

BERGEL, Salvador Darío, “Aspectos éticos y jurídicos de la edición genética humana", Revista de Derecho y Genoma Humano. Genética, Biotecnología y Medicina Avanzada, n 46 (2017), pp. 15-35.

BERNARDINI, Daniele, "Curarsi vs. Prendersi cura. Le scelte del fine vita”, Quaderni Vicentini, no 5 (2017), pp. 87-94.

BRUSCO, Carlo, "Cassazione e responsabilità penale del medico. Tipicità e determinatezza del nuovo art. 590 sexies c.p.", Diritto Penale Contemporaneo, $\mathrm{n}^{\circ} 11$ (2017), pp. 205223. En: https://www.penalecontemporaneo.it/upload/6599-brusco1117.pdf [visitado el 12.01.2018].

BURGSTALLER, Manfred, Das Fahrlässigkeitsdelikt im Strafrecht. Unter besonderer Berücksichtigung der Praxis in Verkehrssachen, Wien: Manz, 1974.

BUSTOS RAMÍREZ, Juan, El delito culposo, Santiago: Ed. Jurídica de Chile, 1995.

CANESTRARI, Stefano, Dolo eventuale e colpa cosciente. Ai confini tra dolo e colpa nella struttura delle tipologie delittuose, Milano: Giuffrè, 1999.

CAPUTO, Matteo, “Agente modello" e responsabilità per colpa in campo sanitario. Problemi e prospettive, Milano: EDU Catt, 2012.

CARNEVALI, Raúl, “Un examen a los problemas de relación de causalidad y de imputación objetiva conforme a la doctrina penal chilena", en: VARGAS PINTO, Tatiana (Ed.), La relación de causalidad. Análisis de su relevancia en la responsabilidad civil y penal, Cuadernos de extensión, $\mathrm{n}^{\circ}$ 15, Santiago: Universidad de los Andes, 2008, pp. 223-240.

CARNEVALI, Raúl, "La justicia restaurativa como mecanismo de solución de conflictos. Su examen desde el derecho penal", Justicia Juris, vol. 13, nº 1 (2017), pp. 122-132. 
Polit. crim. Vol. 13, No 26 (Diciembre 2018) Art. 6, pp. 858-903.

[http://www.politicacriminal.cl/Vol_13/n_26/Vol13N26A6.pdf]

CASTRONUOVO, Donato, La colpa penale, Milano: Giuffrè, 2009.

CENTONZE, Francesco, La normalità dei disastri tecnologici. Il problema del congedo dal diritto penale, Milano: Giuffrè, 2004.

COBOS GÓMEZ DE LINARES, Miguel Ángel, "El problema de las lagunas "conscientes" y la jurisprudencia "creativa" a través de un ejemplo: la distinción entre culpa profesional y culpa del profesional”, Poder Judicial, nº 18 (1990), pp. 113-132.

CONTRERAS, Lautaro, "Reglas extrajurídicas y creaciones de riesgos toleradas o desaprobadas en los delitos culposos de homicidio y lesiones", Política Criminal, Vol. 13, $\quad \mathrm{n}^{\mathrm{o}} \quad 25 \quad$ (2018), 2 pp. 387-444. http://www.politicacriminal.cl/Vol_13/n_25/Vol13N25A11.pdf [visitado el 14.06.2018].

CORCOY BIDASOLO, Mirentxu, El delito imprudente. Criterios de imputación del resultado, Barcelona: PPU, 1989.

CORCOY BIDASOLO, Mirentxu, "Prólogo", en: El delito imprudente. Criterios de imputación del resultado, Montevideo - Buenos Aires: B de F, 2013.

CÓRDOBA RODA, Joan, “Configuración de la imprudencia en el ámbito sanitario en el nuevo Código penal”, Derecho y Salud, Vol. 4, nº 2 (1996), pp. 141-146.

CORNACCHIA, Luigi, Concorso di colpe e principio di responsabilità per fatto proprio, Torino: Giappichelli, 2004.

CUPELLI, Cristiano, "La colpa dello psichiatra. Rischi e responsabilità tra poteri impeditivi, regole cautelari e linee guida", Diritto Penale Contemporaneo (2016), pp. 1-21. En: https://www.penalecontemporaneo.it/upload/1458553545CUPELLI_2016a.pdf [visitado el 12.01.2018].

CUPELLI, Cristiano, "Lo statuto penale della colpa medica e le incerte novità della legge Gelli-Bianco", Diritto Penale Contemporaneo, $\mathrm{n}^{\mathrm{o}} 4$ (2017), pp. 200-216. En: https://www.penalecontemporaneo.it/pdf-

viewer/?file=\%2Ffoto\%2FDPC_Riv_Trim_4_17.pdf\#page=211 [visitado el 14.06.2018].

CUPELLI, Cristiano, "L'eterointegrazione della legge Gelli-Bianco: aggiornamenti in tema di linee guida 'certificate' e responsabilità penale in ambito sanitario", Diritto Penale Contemporaneo, $\quad \mathrm{n}^{\mathrm{o}} \quad 10 \quad$ (2017), pp. 266-271. En: https://www.penalecontemporaneo.it/pdf-viewer/?file=\%2Fpdffascicoli\%2FDPC_10_2017.pdf\#page=266 [visitado el 12.01.2018]. 
PERIN, Andrea. "La redefinición de la culpa (imprudencia) penal médica ante el fenómeno de la medicina defensiva. Bases desde una perspectiva comparada".

CUPELLI, Cristiano, "La legge Gelli-Bianco nell'interpretazione delle Sezioni Unite", Diritto Penale Contemporaneo, $\mathrm{n}^{\mathrm{o}} 12$ (2017), pp. 135-138. En: https://www.penalecontemporaneo.it/pdf-viewer/?file=\%2Fpdffascicoli\%2FDPC_12_2017.pdf\#page=135 [visitado el 12.01.2018].

CUPELLI, Cristiano, “L'art. 590-sexies c.p. nelle motivazioni delle Sezioni Unite: un'interpretazione 'costituzionalmente conforme' dell'imperizia medica (ancora) punibile”, Diritto Penale Contemporaneo, $\mathrm{n}^{\mathrm{o}} 3$ (2018), pp. 246-258. En: https://www.penalecontemporaneo.it/pdf-viewer/?file=\%2Fpdffascicoli\%2FDPC_3_2018.pdf\#page=246 [visitado el 23.04.2018].

CURY URZUA, Enrique, “Contribución al estudio de la responsabilidad médica por hechos culposos”, Revista de Ciencias Penales, t. XXXVII (1981), pp. 97-105.

D'ALESSANDRO, Francesco, “Contributi del diritto alla riduzione della medicina difensiva", Rivista italiana di medicina legale, $\mathrm{n}^{\circ} 3$, (2014), pp. 927-952.

DE FRANCESCO, Gennaro V., "Sulla misura soggettiva della colpa", Studi Urbinati di scienze giuridiche, politiche ed economiche, Nuova Serie A (1977-78), pp. 273-343.

DE LA MAZA GAZMURI, Iñigo, "Presentación”, en: DE LA MAZA G., Iñigo (Coord.), Responsabilidad médica, Cuadernos de análisis jurídico - Colección de Derecho Privado VI, Santiago: Ediciones Universidad Diego Portales, 2010, pp. 9-11.

DE STEFANO, Frank; PRICE, Cristofer S.; WEINTRAUB, Eric S., "Increasing Exposure to Antibody-Stimulating Proteins and Polysaccharides in Vaccines Is Not Associated with Risk of Autism", The Journal of Pediatrics, Vol. 163, Issue 2 (2013), pp. 561567.

DI GIOVINE, Ombretta, "In difesa del c.d. decreto Balduzzi (ovvero: perché non è possibile ragionare di medicina come se fosse diritto e di diritto come se fosse matematica)", Archivio penale, $\mathrm{n}^{\circ} 1$ (2014), pp. 1-23.

DI LANDRO, Andrea R., "I criteri di valutazione della colpa penale del medico, dal limite della "gravità" ex art. 2236 c.c. alle prospettive della gross negligence anglosassone", Indice penale (2004), pp. 733-769.

DI LANDRO Andrea R., Dalle linee guida e dai protocolli all'individualizzazione della colpa penale nel settore sanitario. Misura oggettiva e soggettiva della malpractice, Torino: Giappichelli, 2012.

DONINI, Massimo, "Il dolo eventuale: fatto-illecito e colpevolezza", Diritto Penale Contemporaneo - Rivista Trimestrale, $\mathrm{n}^{\mathrm{o}} 1$ (2014), pp. 70-127. En: http://www.penalecontemporaneo.it/d/2857 [visitado el 12.01.2018].

DONINI, Massimo, "L’elemento soggettivo della colpa. Garanzie e sistematica", Rivista 
Polit. crim. Vol. 13, No 26 (Diciembre 2018) Art. 6, pp. 858-903.

[http://www.politicacriminal.cl/Vol_13/n_26/Vol13N26A6.pdf]

italiana di diritto e procedura penale, Vol. 56, n 1 (2013), pp. 124-156.

ESTEVE PARDO, José, El Desconcierto del Leviatán. Política y Derecho ante las Incertidumbres de las Ciencia, Barcelona: Marcial Pons, 2009.

EUSEBI, Luciano, "Medicina difensiva e diritto penale "criminogeno", Rivista italiana di medicina legale, Vol. XXXIII, nº 5 (2011), pp. 1085-1106.

FEIJÓO SÁNCHEZ, Bernardo José, "La imprudencia en el Código penal de 1995 (cuestiones de lege data y de lege ferenda)", Cuadernos de Política Criminal (1997), pp. 303-365.

FEMENÍA LÓPEZ, Pedro J., "Nuevos perfiles jurídicos del acto médico: responsabilidad derivada del screening genético", Revista de Derecho y Genoma Humano. Genética, Biotecnología y Medicina Avanzada, nº 46 (2017), pp. 143-176.

FIANDACA, Giovanni, Prima lezione di diritto penale, Bari - Roma: Laterza, 2017.

FLETCHER, George P., "The Theory of Criminal Negligence. A Comparative Analysis", University of Pennsylvania Law Review, Vol. 119, nº 3 (1971), pp. 401-438.

FORNASARI, Gabriele, "Dolo, errore sul fatto ed aberratio ictus", en: VV.AA., Introduzione al sistema penale, Vol. II, Torino: Giappichelli, 2001, pp. 155-197.

FORTI, Gabrio, Colpa ed evento nel diritto penale, Milano: Giuffrè, 1990.

FORTI, Gabrio; CATINO, Maurizio; D’ALESSANDRO, Francesco; MAZZUCATO, Claudia; VARRASO, Gianluca, Il problema della medicina difensiva. Una proposta di riforma in materia di responsabilità penale nell'ambito dell'attività sanitaria $e$ gestione del contenzioso legato al rischio clinico, Pisa: ETS, 2010.

FRAKES, Michael D., “The Surprising Relevance of Medical Malpractice Law”, University of Chicago Law Review, Vol. 82, Issue 1 (2015), pp. 317-391. En: https://chicagounbound.uchicago.edu/uclrev/vol82/iss1/13 [visitado el 25.04.2018].

FREITAS DRUMOND, José Geraldo, ¿Será la medicina defensiva el futuro de la medicina?, Gaceta Internacional de Ciencias Forenses, nº 14 (2015), pp. 3-4.

GALLO, Marcello, "Colpa penale (dir. vig.)", Enciclopedia del diritto, t. VII, Milano: Giuffrè, 1960, pp. 624-644.

GARCÍA RIVAS, Nicolás, “La imprudencia «profesional»: una especie a extinguir", en: $E l$ nuevo Código Penal: presupuestos y fundamentos. Libro Homenaje al Profesor Doctor Don Ángel Torío López, Granada: Comares, 1999, pp. 369-386. 
PERIN, Andrea. "La redefinición de la culpa (imprudencia) penal médica ante el fenómeno de la medicina defensiva. Bases desde una perspectiva comparada".

GARRIDO MONTT, Mario, Derecho Penal: Parte General, t. II, Santiago: Editorial Jurídica de Chile, 1997.

GIUNTA, Fausto, "La normatività della colpa. Lineamenti di una teorica", Rivista italiana di diritto e procedura penale, Vol. 42 (1999), pp. 86-115.

GIUNTA, Fausto, "Protocolli medici e colpa penale secondo il «decreto Balduzzi»", Rivista italiana di medicina legale, Vol. 35, nº 2 (2013), pp. 819-832.

GÓMEZ PAVÓN, Pilar, Tratamientos médicos: su responsabilidad penal y civil, Barcelona: Bosch, 2013.

GÓMEZ RIVERO, Maria del Carmen, La responsabilidad penal del médico, Valencia: Tirant lo Blanch, 2008.

GRATACÓS GÓMEZ, Nuria, "La imprudencia en el nuevo código penal. Especial referencia de la imprudencia profesional y la inhabilitación especial para el ejercicio de una profesión, oficio o cargo", Derecho y Salud, Vol. 5, no 1 (1997), pp. 62-75.

GRECO, Monica, "What is the DSM? Diagnostic manual, cultural icon, political battleground: an overview with suggestions for a critical research agenda", Psychology \& Sexuality, Vol. 7, Issue 1 (2016), pp. 6-22. En: https://doi.org/10.1080/19419899.2015.1024470 [visitado el 14.06.2018].

GUERRA, Giorgia, "La medicina difensiva: fenomeno moderno dalle radici antiche", Politiche sanitarie, Vol. 14, $\mathrm{n}^{\mathrm{o}} 4$ (2013), pp. 221-225. En: http://www.politichesanitarie.it/articoli.php?archivio=yes\&vol_id=1410\&id=15655 [visitado el 12.01.2018].

GUTIÉRREZ ARANGUREN, José Luis, "La imprudencia profesional", en: JUANE SÁNCHEZ, Miguel, et al (Coord.), Lecciones de derecho sanitario (1999), pp. 391408.

HALL, Jerome, "Negligent Behavior should be excluded from Penal Liability", Columbia Law Review, Vol. 63, no 4 (1963), pp. 632-644. En: http://www.jstor.org/stable/1120580?origin=JSTOR-pdf [visitado el 12.01.2018].

HASKEL, Michael A., "A proposal for addressing the effects of hindsight and positive outcome biases in medical malpractice cases", Tort Trial \& Insurance Practice Law Journal, Vol. 42, $\mathrm{n}^{\mathrm{o}} 3$ (2007), pp. 895-940. En: https://www.jstor.org/stable/25763860?seq=1\#page_scan_tab_contents [visitado el 12.01.2018].

HAVA GARCÍA, Esther, La imprudencia médica, Valencia: Tirant lo Blanch, 2001. 
Polit. crim. Vol. 13, No 26 (Diciembre 2018) Art. 6, pp. 858-903.

[http://www.politicacriminal.cl/Vol_13/n_26/Vol13N26A6.pdf]

HERNÁNDEZ BASUALTO, Héctor, “Consentimiento informado y responsabilidad penal médica: una relación ambigua y problemática”, en: DE LA MAZA GAZMURI, Iñigo (Coord.), Responsabilidad médica, Cuadernos de análisis jurídico - Colección de Derecho Privado VI, Santiago: Ediciones Universidad Diego Portales, 2010, pp. 167185.

IADECOLA, Gianfranco, "Qualche riflessione sulla nuova disciplina per colpa medica per imperizia nella Legge 8 marzo 2017 N. 24 (Legge cd. Gelli-Bianco)", Diritto Penale Contemporaneo, $\quad \mathrm{n}^{\mathrm{o}} \quad 6 \quad$ (2017), pp. 53-66. En: https://www.penalecontemporaneo.it/upload/9522-iadecola617.pdf [visitado el 13.01.2018].

JORGE-BARREIRO, Agustín, “Aspectos básicos de la imprudencia punible en la actividad médico-quirúrgica”, Estudios Penales y Criminológicos, n 14 (1989-90), pp. 138-175.

KALICHMAN, Seth C., Denying AIDS: Conspiracy Theories, Pseudoscience, and Human Tragedy, New York: Springer, 2009.

KESSLER, Daniel P., "Evaluating the Medical Malpractice System and Options for Reform", The Journal of Economic Perspectives: A Journal of the American Economic Association, Vol. $25 \quad \mathrm{n}^{\mathrm{o}} 2$ (2011), pp. 93-110. En: https://www.ncbi.nlm.nih.gov/pubmed/21595327 [visitado el 12.01.2018].

KUHN, Thomas S., The Structure of Scientific Revolutions (1962), Chicago - London: The University of Chicago Press, 2012.

LAUTA, Kristian C., Disaster Law, Abingdon - New York: Routledge, 2015.

LEÓN CORREA, Francisco J., "Autonomía y beneficencia en la ética clínica: ni paternalismo ni medicina defensiva", Biomedicina, Vol. 2, no 3 (2006), pp. 257-260.

LICCI, Giorgio, Immagini di conoscenza giuridica, Padova: Cedam - Wolters Kluwer Italia, 2011.

MAGLIO, Ignacio, "Error y medicina a la defensiva: ética médica y la seguridad del paciente", Revista Bioética, Vol. 19, no 2 (2011), pp. 359-365.

MAÑALICH RAFFO, Juan P., "La imprudencia como estructura de imputación”, Revista de Ciencias Penales, Vol. XLII, nº 3 (2015), pp. 13-36.

MANNA, Adelmo, Profili penalistici del trattamento medico-chirurgico, Milano: Giuffrè, 1984.

MANNA, Adelmo, Medicina difensiva e diritto penale. Tra legalità e tutela della salute, Pisa: Pisa University Press, 2014. 
PERIN, Andrea. "La redefinición de la culpa (imprudencia) penal médica ante el fenómeno de la medicina defensiva. Bases desde una perspectiva comparada".

MARAVER GÓMEZ, Mario, El principio de confianza en Derecho penal. Un estudio sobre la aplicación del principio de autorresponsabilidad en la teoría de la imputación objetiva, Cizur Menor: Civitas - Thomson Reuters, 2009.

MARINUCCI, Giorgio, La colpa per inosservanza di leggi, Milano: Giuffrè, 1965.

MARTÍNEZ, Marco, "La graduación del deber de cuidado en el delito culposo por Actos de mala praxis médica: un análisis dogmático, jurisprudencial y económico", Política Criminal, Vol. 6, $\mathrm{n}^{\mathrm{o}} 12$ (2011), pp. 214-252. En: http://www.politicacriminal.cl/Vol_06/n_12/Vol6N12A1.pdf [visitado el 12.01.2018].

MASSARO, Antonella, "L'art. 590-sexies c.p., la colpa per imperizia del medico e la camicia di Nesso dell'art. 2236 c.c.", Archivio Penale, $\mathrm{n}^{\circ} 3$ (2017), pp. 1-52. En: http://www.archiviopenale.it/File/DownloadArticolo?codice=0ccdde58-a33c-4327824e-23e05851b6a5\&idarticolo=15217 [visitado el 23.04.2018].

MATUS ACUÑA, Jean Pierre, "Mala praxis como sinónimo de negligencia y la «normativización» de la responsabilidad penal médica en la reciente jurisprudencia de la Corte Suprema de Chile ¿Un camino hacia la responsabilidad penal objetiva?”, (2009). En: http://www.microjuris.cl/home.jsp [visitado el 12.01.2018].

MELCHIONDA, Alessandro, "Definizioni normative e riforma del codice penale (spunti per una rinnovata riflessione sul tema)", en: CADOPPI, Alberto (Ed.), Omnis definitio in iure periculosa? Il problema delle definizioni legali nel diritto penale, Padova: Cedam, 1996, pp. 391-429.

MELCHIONDA, Alessandro, "Forme di colpevolezza e prospettive di codificazione europea. Brevi riflessioni sulle auspicate revisioni normative dei confini fra dolo e colpa", en: CADOPPI, Alberto (Ed.), Verso un nuovo codice penale modello per l'Europa. Offensività e colpevolezza, Padova: Cedam, 2002, pp. 185-201.

MICHELETTI, Dario, "La normatività della colpa medica nella giurisprudenza della Cassazione”, en: CANESTRARI, Stefano; GIUNTA, Fausto; GUERRINI, Roberto; PADOVANI, Tullio (Eds.), Medicina e diritto penale, Pisa: Edizioni ETS, 2009, pp. 247-283.

MIRANDA SUÁREZ, Francisco, "Demandas por responsabilidad médica en Chile. Análisis de montos, condenas y duración”, Revista de Derecho. Escuela de Postgrado, no 7 (2015), pp. 79-102.

MONTANARI VERGALLO, Gianluca, Il rapporto medico-paziente. Consenso e informazione tra libertà e responsabilità, Milano: Giuffrè, 2008.

MONTANARI VERGALLO, Gianluca, La colpa sanitaria verso la fase del bilanciamento: analisi de iure condito e proposte di riforma, Milano: Giuffrè, 2016. 
Polit. crim. Vol. 13, No 26 (Diciembre 2018) Art. 6, pp. 858-903.

[http://www.politicacriminal.cl/Vol_13/n_26/Vol13N26A6.pdf]

MONTANARI VERGALLO, Gianluca; RINALDI, Raffaella; BERSANI, Giuseppe; MARINELLI, Enrico, "Medico-legal notes for a new set of standards in the assessment of penal liability in psychiatry”, Rivista di psichiatria, Vol. 52, n 1 (2017), pp. 16-23, en:

http://www.rivistadipsichiatria.it/articoli.php?archivio=yes\&vol_id=2631\&id=27050 [visitado el 14.06.2018].

NÁQUIRA RIVEROS, Jaime, Derecho Penal Chileno. Parte General, t. I, Santiago: Legal Publishing Chile, 2015.

OEBERST, Aileen; GOECKENJAN, Ingke, "When being wise after the event results in injustice: Evidence for hindsight bias in judges' negligence assessments", Psychology, Public Policy, and Law, Vol. 22, $\mathrm{n}^{\mathrm{o}} 3$ (2016), pp. 271-279. En: http://psycnet.apa.org/doiLanding?doi=10.1037\%2Flaw0000091 [visitado el 12.01.2018].

ORTEGA GONZÁLEZ, Manuel; MÉNDEZ RODRÍGUEZ, Juan Manuel; LÓPEZ-LÓPEZ, Fidel, "Medicina defensiva, su impacto en las instituciones de salud", Revista Conamed, Vol. 14 (2009), pp. 4-10.

PAREDES SIERRA, Raymundo; RIVERO SERRANO, Octavio, "Medicina defensiva", en: TONIMOTO, Miguel; RIVERO SERRANO, Octavio (Coords.), El ejercicio actual de la medicina, Facultad de Medicina UNAM - Siglo XXI Editores, 2003, pp. 79-89.

PERIN, Andrea, "La crisi del "modello nomologico" fra spiegazione e prevedibilità dell'evento nel diritto penale. Note introduttive e questioni preliminari sul fatto tipico colposo", Rivista italiana di diritto e procedura penale, Vol. 57, nº 3 (2014), pp. 13711409.

PERIN, Andrea, "La contribución de la víctima y la imputación objetiva del resultado en la teoría del delito imprudente. Un estudio comparado en materia de prevención de riesgos laborales", Revista Electrónica de Ciencia Penal y Criminología, n ${ }^{\circ} 18$ (2016), pp. 1-27. En: http://criminet.ugr.es/recpc/18/recpc18-03.pdf [visitado el 12.01.2018].

PERIN, Andrea, "La condotta lesiva colposa. Una prospettiva ricostruttiva", Política Criminal, Vol. 12, $\mathrm{n}^{\mathrm{o}} 23$ (2017), pp. 207-266. En: http://www.politicacriminal.cl/Vol_12/n_23/Vol12N23A7.pdf [visitado el 12.01.2018].

PETERS, Philip G. Jr., "The Role of Jury in Modern Malpractice Law”, Iowa Law Review, Vol. 87 (2002), pp. 909-970. En: https://ssrn.com/abstract=310681 [visitado el 12.01.2018]. 
PERIN, Andrea. "La redefinición de la culpa (imprudencia) penal médica ante el fenómeno de la medicina defensiva. Bases desde una perspectiva comparada".

PIZARRO W., Carlos, "Responsabilidad profesional médica: Diagnóstico y perspectivas", Revista Médica de Chile, Vol. 136, no 4 (2008), pp. 539-543.

POLITOFF LIFSCHITZ, Sergio; MATUS ACUÑA, Jean Pierre; RAMÍREZ GUZMÁN, María Cecilia, Lecciones de Derecho Penal Chileno. Parte General, Santiago: Editorial Jurídica de Chile, 2003.

PREDA, Alex, AIDS, Rhetoric, and Medical Knowledge, Cambridge: Cambridge University Press, 2005.

PULITANÒ, Domenico, "Responsabilità medica: letture e valutazioni divergenti del novum legislativo", Diritto Penale Contemporaneo - Rivista Trimestrale, no 4 (2013), pp. 73 85. En: https://www.penalecontemporaneo.it/d/2269 [visitado el 12.01.2018].

QUINTANO RIPOLLÉS, Antonio, Derecho penal de la culpa (imprudencia), Barcelona: Bosch, 1958.

REYES ROMERO, Ítalo, "Sobre la construcción de la exigencia de cuidado", Política Criminal, Vol. 10, $\mathrm{n}^{\mathrm{o}} 19 \quad$ (2015), pp. 56-91. En: http://www.politicacriminal.cl/Vol_10/n_19/Vol10N19A3.pdf [visitado el 12.01.2018].

REYES ROMERO, Ítalo, "Una aproximación a la imputación a título de imprudencia en el Código penal chileno", Revista de Derecho de la Pontificia Universidad Católica de Valparaíso, Vol. XLVII (2016), pp. 245-278.

RISICATO, Lucia, L'attività medica di équipe tra affidamento e obblighi di controllo reciproco. L'obbligo di vigilare come regola cautelare, Torino: Giappichelli, 2013.

RODRÍGUEZ VÁZQUEZ, Virgilio, "El delito de tratamiento médico arbitrario", Revista Electrónica Ciencia Penal y Criminología, 19-3 (2017), pp. 1-59. En: http://criminet.ugr.es/recpc/19/recpc19-03.pdf [visitado el 12.01.2018].

ROIATI, Alessandro, Medicina difensiva e colpa professionale medica in diritto penale. Tra teoria e prassi giurisprudenziale, Milano: Giuffrè, 2012.

ROIATI, Alessandro, "Linee guida, buone pratiche e colpa grave: vera riforma o mero placebo?", Diritto penale e processo, no 2 (2013), pp. 216-229.

ROMEO CASABONA, Carlos María, "Los delitos culposos en la reforma penal”, Anuario de derecho penal y ciencias penales, Tomo 43, $\mathrm{n}^{\circ} 2$ (1990), pp. 443-496.

ROMEO CASABONA, Carlos María, "Evolución del tratamiento jurídico-penal de la imprudencia del personal médico-sanitario”, Revista Jurídica de Castilla y León, n 13 (2007), pp. 211-251. 
Polit. crim. Vol. 13, No 26 (Diciembre 2018) Art. 6, pp. 858-903.

[http://www.politicacriminal.cl/Vol_13/n_26/Vol13N26A6.pdf]

ROMEO CASABONA, Carlos María, Conducta peligrosa e imprudencia en la sociedad de riesgo, Granada: Comares, 2005.

ROMEO CASABONA, Carlos María, El médico y el Derecho Penal, t. I, La actividad curativa. Licitud y responsabilidad penal, Santa Fe: Rubinzal - Culzoni, 2011.

ROMEO CASABONA, Carlos María, El médico y el Derecho Penal, t. II, Vol. 1, Los problemas penales actuales de la Biomedicina, Santa Fe: Rubinzal - Culzoni, 2011.

ROMEO CASABONA, Carlos María, "El tipo del delito de acción imprudente", en: ROMEO CASABONA, Carlos M.; SOLA RECHE, Esteban; BOLDOVA PASAMAR, Miguel Á. (Coords.), Derecho penal. Parte general - Introducción a la teoría jurídica del delito (2 ${ }^{\mathrm{a}}$ ed.), Granada: Comares, 2016, pp. 133-148.

ROMEO CASABONA, Carlos María; URRUELA MORA, Asier, El establecimiento de un sistema nacional de notificación y registro de eventos adversos en el sector sanitario: aspectos legales, Granada: Comares, 2010.

ROMEO CASABONA, Carlos María (Ed.), Tecnología convergentes: desafíos éticos y jurídicos, Cátedra Interuniversitaria de Derecho y Genoma Humano - Comares: Bilbao - Granada, 2016.

ROMEO MALANDA, Sergio, "Responsabilidad penal médica por ausencia del consentimiento informado: un enfoque alternativo a las tesis dominantes", Cuadernos

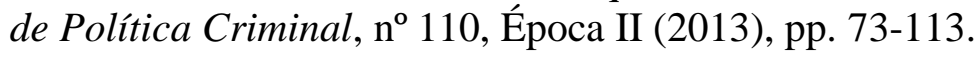

ROSAS OLIVA, Juan Ignacio, "La delimitación del deber de cuidado en la imputación de responsabilidad penal por imprudencia médica”, Doctrina y jurisprudencia penal. Imprudencia penal médica, nº 5 (2011), pp. 3-34.

RUEDA MARTÍN, M. Ángeles, "La concreción del deber objetivo de cuidado en el desarrollo de la actividad médico-quirúrgica curativa", InDret Penal, no 4 (2009), pp. 1-58. En: http://www.indret.com/pdf/672.pdf [visitado el 12.01.2018].

RUIZ LÓPEZ, Carmen Eloísa, La graduación del delito imprudente. Reflexiones sobre la necesidad de delimitación entre imprudencia leve e imprudencia grave, Bogotá: Universidad Externado de Colombia, 2011.

SCLAR, David; HOUSMAN, Michael, "Medical Malpractice and Physician Liability: Examining Alternatives to Defensive Medicine", Harvard Health Policy Review, Vol. 4, $\mathrm{n}^{\mathrm{o}} 1$ (2003), pp. 75-84. En: https://ssrn.com/abstract=924294 [visitado el 12.01.2018].

SILVA SÁNCHEZ, Jesús María, Medicinas alternativas e imprudencia médica, Barcelona: Bosch, 1999. 
PERIN, Andrea. "La redefinición de la culpa (imprudencia) penal médica ante el fenómeno de la medicina defensiva. Bases desde una perspectiva comparada".

STRATENWERTH, Günther, "L'individualizzazione della misura di diligenza nel delitto colposo", Rivista italiana di diritto e procedura penale, Vol. 29, nº 3 (1986), pp. 635652.

TALLACCHINI, Maria Chiara, "Before and beyond the precautionary principle: Epistemology of uncertainty in science and law", Toxicology and Applied Pharmacology, Vol. 207, Issue 2 (2005, Supplement), pp. 645-651. En: http://www.sciencedirect.com/science/article/pii/S0041008X05003303?via\%3Dihub [visitado el 12.01.2018].

THE LANCET (EDS.), "Retraction-Ileal-lymphoid-nodular hyperplasia, non-specific colitis, and pervasive developmental disorder in children", The Lancet, Vol. 375, Issue 9713 (2010), 445.

TINICA, Grigore; TOMAZIU-TODOSIA, Mihaela; TOMAZIU-TODOSIA GabrielCatalin; CHISTOL, Raluca Ozana; BULGARU-ILIESCU, Diana; FURNICA Cristina, "Defensive Medicine: Myths and Realities" En: IGNATESCU, C.; SANDU, A.; CIULEI, T. (Eds.), Rethinking Social Action. Core Values in Practice, Suceava: Lumen Proceedings, 2017, pp. 898-910.

TOMASI, Marta, "Uniformità della giurisprudenza e unitarietà della scienza: la misura di sostenibilità del pluralismo", BioLaw Journal, $\mathrm{n}^{\mathrm{o}} 1$ (2016), pp. 81-103. En: http://www.biodiritto.org/ojs/index.php?journal=biolaw\&page=article\&op=view\&pat $\mathrm{h} \% 5 \mathrm{~B} \% 5 \mathrm{D}=128$ [visitado el 31.05.2018].

TORÍO LÓPEZ, Ángel, "El deber objetivo de cuidado en los delitos culposos", Anuario de Derecho Penal y Ciencias Penales (1974), pp. 25-59.

URRUELA MORA, Asier, El derecho penal ante el fenómeno de las agresiones a profesionales sanitarios, Granada: Comares, 2017.

URRUELA MORA, Asier; ROMEO MALANDA, Sergio, Tendencias actuales de la jurisprudencia española, en: ROMEO CASABONA, Carlos M., El médico y el Derecho Penal, t. II, Vol. 1, Los problemas penales actuales de la Biomedicina, Santa Fe: Rubinzal - Culzoni, 2011, pp. 579-605.

U.S. CONGRESS - OFFICE OF TECHNOLOGY ASSESSMENT, Defensive Medicine and Medical Malpractice, Washington DC: U.S. Government Printing Office, 1994.

VALBONESI, Cecilia, "Linee guida e protocolli per una nuova tipicità dell'illecito colposo", Rivista italiana di diritto e procedura penale, Vol. 56, nº 1 (2013), pp. 250-301.

VALLINI, Antonio, "Paternalismo medico, rigorismo penali, medicina difensiva: una sintesi problematica e un azzardo de iure condendo", Rivista italiana di medicina legale, Vol. XXXV, no 1 (2013), pp. 1-16. 
Polit. crim. Vol. 13, No 26 (Diciembre 2018) Art. 6, pp. 858-903.

[http://www.politicacriminal.cl/Vol_13/n_26/Vol13N26A6.pdf]

VALLINI, Antonio, “L'art. 3 del "Decreto Balduzzi” tra retaggi dottrinali, esigenze concrete, approssimazioni testuali, dubbi di costituzionalità", Rivista italiana di medicina legale, Vol. XXXV, no 2 (2013), pp. 736-750.

VALLINI, Antonio, "Linee guida e colpa medica nel quadro teorico del "concorso di regole cautelari”. Un'interpretazione teleologica, e conforme alla lettera, dell'art. 590 sexies CP", Legislazione penale (2017), pp. 1-30. En: http://www.lalegislazionepenale.eu/wp-content/uploads/2017/12/Antonio-ValliniLinee-guida-e-colpa-medica-Approfondimenti-def..pdf [visitado el 23.04.2018].

VAN WEEZEL DE LA CRUZ, Alex, "Parámetros para el enjuiciamiento de la infracción al deber de cuidado en los delitos imprudentes", Revista Chilena de Derecho, Vol. 26, $\mathrm{n}^{\circ}$ 2 (1999), pp. 323-336.

VARGAS PINTO, Tatiana, "La imprudencia médica. Algunos problemas de imputación de lo injusto penal", Revista de Derecho UCN, Vol. 17, no 2 (2010), pp. 99-132. En: http://revistaderecho.ucn.cl/index.php/rducn/article/view/102/102 [visitado el 12.01.2018].

VARGAS PINTO, Tatiana, "Algunos antecedentes sobre el complejo "deber de previsión" médico", Revista de Derecho (Valdivia), Vol. XXX, no 1 (2017), pp. 351-375. En: http://www.scielo.cl/pdf/revider/v30n1/art15.pdf [visitado el 12.01.2018].

VARGAS PINTO, Tatiana, Responsabilidad penal por imprudencia médica. Un examen práctico de los principales problemas para la determinación del cuidado debido, Santiago: Der Ediciones, 2017.

VENEZIANI, Paolo, Regole cautelari "proprie" ed "improprie" nella prospettiva delle fattispecie colpose causalmente orientate, Padova: Cedam, 2003.

VILLA, Vittorio, Teorie della scienza giuridica e teorie delle scienze naturali. Modelli ed analogie, Milano: Giuffrè, 1984.

WELZEL, Hans, Fahrlässigkeit und Verkehrsdelikte. Zur Dogmatik der fahrlässigen Delikte, Karlsruhe: Müller, 1961.

ZUGALDÍA ESPINAR, José Miguel, "La infracción del deber individual de cuidado en el sistema del delito culposo", Anuario de Derecho Penal y Ciencias Penales, Vol. 2 (1984), pp. 321-332. 